\title{
Canopy architectural and physiological characterization of near-isogenic wheat lines differing in the tiller inhibition gene tin
}

\author{
Carina Moeller ${ }^{1 *}$, Jochem B. Evers ${ }^{2}$ and Greg Rebetzke ${ }^{3}$ \\ 1 Tasmanian Institute of Agriculture, University of Tasmania, Hobart, TAS, Australia \\ ${ }^{2}$ Centre for Crop Systems Analysis, Wageningen University, Wageningen, Netherlands \\ ${ }^{3}$ Commonwealth Scientific and Industrial Research Organisation Plant Industry, Black Mountain Laboratories, Black Mountain, ACT, Australia
}

\section{Edited by:}

Sergey Shabala, University of

Tasmania, Australia

Reviewed by:

Lars Hendrik Wegner, Karlsruhe Institute of Technology, Germany

Colin James Birch, University of

Tasmania, Australia

*Correspondence:

Carina Moeller, Tasmanian Institute of Agriculture, University of

Tasmania, Private Bag 98,

Hobart TAS 7001, Australia

e-mail: carina.moeller@utas.edu.au
Tillering is a core constituent of plant architecture, and influences light interception to affect plant and crop performance. Near-isogenic lines (NILs) varying for a tiller inhibition (tin) gene and representing two genetic backgrounds were investigated for tillering dynamics, organ size distribution, leaf area, light interception, red: far-red ratio, and chlorophyll content. Tillering ceased earlier in the tin lines to reduce the frequencies of later primary and secondary tillers compared to the free-tillering NILs, and demonstrated the genetically lower tillering plasticity of tin-containing lines. The distribution of organ sizes along shoots varied between NILs contrasting for tin. Internode elongation commenced at a lower phytomer, and the peduncle was shorter in the tin lines. The flag leaves of tin lines were larger, and the longest leaf blades were observed at higher phytomers in the tin than in free-tillering lines. Total leaf area was reduced in tin lines, and non-tin lines invested more leaf area at mid-canopy height. The tiller economy (ratio of seed-bearing shoots to numbers of shoots produced) was $10 \%$ greater in the tin lines $(0.73-0.76)$ compared to the free-tillering sisters $(0.62-0.63)$. At maximum tiller number, the red: far-red ratio (light quality stimulus that is thought to induce the cessation of tillering) at the plant-base was 0.18-0.22 in tin lines and 0.09-0.11 in free-tillering lines at levels of photosynthetic active radiation of $49-53 \%$ and $30-33 \%$, respectively. The tin lines intercepted less radiation compared to their free-tillering sisters once genotypic differences in tiller numbers had established, and maintained green leaf area in the lower canopy later into the season. Greater light extinction coefficients $(k)$ in tin lines prior to, but reduced $k$ after, spike emergence indicated that differences in light interception between NILs contrasting in tin cannot be explained by leaf area alone but that geometric and optical canopy properties contributed. The careful characterization of specifically-developed NILs is refining the development of a physiology-based model for tillering to improve understanding of the value of architectural traits for use in cereal improvement.

Keywords: wheat, tillering plasticity, tiller inhibition gene, tin, organ sizes, radiation interception, red: far-red ratio

\section{INTRODUCTION}

Tillering refers to the growth of lateral shoots from axillary meristems at the plant base in Poaceae species such as wheat (Triticum aestivum L.) and barley (Hordeum vulgare L.) (Assuero and Tognetti, 2010), and is an important constituent of canopy architecture. By varying tiller number, the subsequent size and display of leaf area, and ultimately spike number, individuals in a plant stand adapt dynamically to the availability of resources chiefly light, water, and nutrients (Kirby and Faris, 1972; Schmitz and Theres, 2005; Assuero and Tognetti, 2010). Genotypic variation in the degree of tillering has been documented for different species (e.g., Richards, 1988; Dofing and Karlsson, 1993; Ishikawa et al., 2005; Borràs et al., 2009). In wheat, a North African landrace showing an uniculm phenotype was uncovered about 40 years ago (Atsmon and Jacobs, 1977). Since then, restricted tillering from this landrace has been assessed and reported to be associated with a major gene named tin (for tiller inhibition) mapped to the short arm of chromosome 1A (Spielmeyer and Richards, 2004). More recently, near-isogenic lines (NILs) have been developed that are genetically similar except for the presence or absence of the tin gene (e.g., Mitchell et al., 2012; Sadras and Rebetzke, 2013). Depending on genetic background, there are strongly restricted and semi-restricted tin lines producing phenotypes ranging from uniculm to bi- and oligo-culm plants (Mitchell et al., 2012, 2013). The NILs contrasting in tin allow new opportunities for exploring relationships between extent of tillering and canopy architecture, and provide an ideal model system as the major source for genetic differences in tillering is sufficiently known. Other characteristics of tin genotypes are increased seed numbers per spike, and larger, heavier seeds (Richards, 1988; 
Duggan et al., 2005a,b; Mitchell et al., 2012, 2013; Sadras and Rebetzke, 2013).

Detailed morphological studies on a near-isogenic pair differing in tin showed that axillary buds developed normally in a tin line strongly restricted in tillering (Kebrom et al., 2012). However, the outgrowth of tiller buds during the transition of the main shoot apex from vegetative to reproductive growth ceased earlier in the tin than in the free-tillering NIL (Kebrom et al., 2012). As a consequence, the tin line produced fewer tillers than its freetillering sibling. The mechanisms controlling bud outgrowth in tin-containing genotypes are arguably not well understood. It has been observed that the basal internodes in the strongly restricted tin line, which were solid rather than hollow, elongate earlier compared to the free-tillering line. This has been hypothesized to divert sucrose away from developing tiller buds arresting bud growth (Kebrom et al., 2012). However, the magnitude of the suppression of tiller bud outgrowth varies between tin-containing lines suggesting that there are interactions between tin and other genes to affect final tiller number (Richards, 1988; Mitchell et al., 2013).

Under conditions favorable for growth, there is close synchrony between tiller and leaf appearance, and the first tiller typically appears when the third leave on the main shoot is fully expanded (Klepper et al., 1983; Kirby and Appleyard, 1987). There is large phenotypic plasticity in maximum tiller number, which is modulated by environmental cues including shading, and the availability of water and nutrients (Sharma, 1995; Prystupa et al., 2003; Sadras and Slafer, 2012; Allard et al., 2013). In addition to competition for resources, changes in light quality, represented by the ratio between red and far-red light intensity (R:FR), sensed by phytochrome at the plant base have been proposed to induce the cessation of tillering (Smith et al., 1990; Davis and Simmons, 1994). A lowered R:FR in the light reflected from neighboring vegetation acts as an early warning signal for future competition before photo-assimilates become scarce (Casal et al., 1986; Franklin and Whitelam, 2005). In free-tillering (non-tin) wheat grown at varying plant densities, Evers et al. (2006) showed that tillering ceased consistently when R:FR dropped below 0.35 0.4 and levels of photosynthetic-active radiation intercepted by the canopy exceeded $40-45 \%$. It is unknown if tillering in tin genotypes responds to an R:FR signal, and if there are differences in the response to R:FR between NILs contrasting for tin.

Following the cessation of tillering, shoot numbers decline to varying degrees until anthesis and sometimes soon after (Kirby and Faris, 1972; García del Moral and García del Moral, 1995). Tillers die as a consequence of plant internal competition for limited resources with allocation directed firstly to the main shoot at the expense of the phenologically younger primary and higherorder tillers (Lauer and Simmons, 1988). In wheat, up to $60 \%$ of tillers can abort and die under normal field conditions (Stapper and Fischer, 1990; Sharma, 1995; Berry et al., 2003; Duggan et al., 2005b). Tiller mortality has been associated with a net loss of dry matter as there is no net redistribution of assimilate from non-surviving shoots (Berry et al., 2003), and is often negatively correlated with seed yield (Sharma, 1995; Berry et al., 2003). It has been argued that increasing the ratio of productive, seed-bearing tillers to the maximum number of tillers (tiller economy) can improve resource-use efficiency to increase crop yields (Richards, 1988; Sharma, 1995; Kebrom et al., 2012). Calculated from data of Mitchell et al. (2013), the tiller economy of five tin-containing NILs was $+8 \%$ under mild and $+16 \%$ under severe terminal water-stress, but only $+3 \%$ when the tin lines were irrigated. However, the association between reduced tillering, greater tiller economy and yield is not clear cut. When Mitchell et al. (2013) compared the NILs under mild water-stress, strongly restricted tin lines increased seed yield by $11 \%$ while semi-restricted $t i n$ lines decreased yield by $15 \%$. Under severe water-stress, both reducedand free-tillering NILs produced similar yields. In irrigated environments, the seed yield of tin-containing lines was reduced by 9 to 24\% (Duggan et al., 2005a; Mitchell et al., 2013), and hence the plant's ability to respond more plastically to resources supply was advantageous.

Lower tiller numbers in tin-containing lines would influence the subsequent size and distribution of leaf area within the plant, and the vertical distribution and interception of radiation by the canopy. Contrasts in light levels in a plant stand caused by mutual shading of individual leaves or incomplete ground-cover at maximum canopy expansion can restrain growth and ultimately yield (Duvick, 2005; Amthor, 2010). However, canopy architecture has remained an under-explored trait in plant breeding despite that changes to architectural attributes such as the sizes, number, and display of leaves could improve the efficiency of radiation interception and therefore plant performance (Long et al., 2006). This may be partly because detailed measurements of architectural attributes are time consuming and tedious, and partly because architecture is only one of many constituent traits of seed yield. Architectural differences between NILs contrasting in tin have not been quantified in detail; however, Richards (1988) reported that the area of the flag and penultimate leaf was greater in tin genotypes compared to free-tillering lines. Duggan et al. (2005b) found similar leaf area indices (LAI; unit leaf area per unit ground area) and light interception in lines contrasting for tin, and suggested that larger leaves in tin genotypes may compensate for an overall reduction in leaf number per plant. Mitchell et al. (2013) reported that strongly restricted tin lines produced lower LAIs and intercepted less radiation, while semi-restricted tin lines performed similar to their free-tillering sisters.

The NILs contrasting for tin provide a unique model system to explore relationships between tillering, canopy architecture, and resource capture. The current study aims to explore the architectural basis for differences in light capture in NILs contrasting for tin and representing two contrasting genetic backgrounds. The relationships were assessed in terms of leaf and tiller appearance, sizes of fully grown organs, and light quality and quantity. This study is a first step in the development of an architectural model (Vos et al., 2010; Evers and Vos, 2013) of tin phenotypes-a tool that could assist in the identification of desirable plant architectural traits for use in trait-based selection (Long et al., 2006; Richards et al., 2010; Rebetzke et al., 2013).

\section{METHODS AND MATERIALS SITE AND GENOTYPES}

Experiments with two pairs of NILs contrasting for the tin gene $\left(\mathrm{B}_{\text {tin }}\right.$ and $\mathrm{B} ; 7770_{\text {tin }}$ and 7770) were conducted in 2012 
and 2013 at experimental sites in Canberra, Australia $\left(35.20^{\circ} \mathrm{S}\right.$, $\left.149.08^{\circ} \mathrm{E}\right)$. The location is characterized by a semi-arid moisture regime (Williams et al., 2002), and has an average annual rainfall of around $616 \mathrm{~mm}$, and average annual minimum and maximum temperatures of $6.5^{\circ} \mathrm{C}$ and $19.7^{\circ} \mathrm{C}$, respectively (Bureau of Meteorology, 2014). The source of tin in line $B_{\text {tin }}$ was the Israeli uniculm line 492 (Atsmon et al., 1986). The NILs $\mathrm{B}_{\text {tin }}$ and $\mathrm{B}$ (also referred to as $\mathrm{B}+$ and $\mathrm{B}$ - in literature) have been used in different studies (e.g., Richards, 1988; Kebrom et al., 2012), and were obtained from a population developed by crossing line 492 to the Australian cultivar Banks with subsequent backcrossing to generate a $\mathrm{BC}_{5}$-derived line that was homozygous for tin. The source of tin in line $7770_{\text {tin }}$ was the CSIRO line CS971. The NILs $7770_{\text {tin }}$ and 7770 (also referred to as $7770 \mathrm{P}$ and $7770 \mathrm{~N}$ in literature) were developed by crossing a Silverstar-based, tin-containing NIL to the cultivar Wyalkatchem, and subsequent backcrossing to Wyalkatchem before inbreeding to produce $\mathrm{BC}_{1} \mathrm{~F}_{5: 6}$ plants heterozygous for tin. These plants were then self-pollinated to develop a pair of lines near-isogenic for tin. The presence of tin was confirmed by genotyping with a tightly linked wheat SSR marker gwm136 (Spielmeyer and Richards, 2004).

\section{EXPERIMENTAL CONDITIONS}

In 2012, wheat was sown after the winter frost period (13/09) in the field at the Ginninderra experiment station, Canberra. The row spacing was $0.2 \mathrm{~m}$ and the sowing depth $0.05 \mathrm{~m}$. Fertilizer nitrogen $(\mathrm{N})$ was drilled into the soil at planting at a rate of $25 \mathrm{~kg}$ $\mathrm{N} /$ ha. A second rate of $15 \mathrm{~kg} \mathrm{~N} /$ ha was broadcast at early stem elongation (29/10). Fungicide (Prosaro ${ }^{\circledR}$ ) was sprayed twice to prevent diseases. The genotypes were grown at two plant densities in irrigated and rain-fed environments in a randomized block design with three replications per treatment combination. Irrigation was applied to the irrigated block on $30 / 10(25 \mathrm{~mm})$ and $22 / 11(20 \mathrm{~mm})$. The size of individual plots was $5 \mathrm{~m}^{2}$. The stands were thinned when plants had about three to four leaves to achieve a low (LD; target plant density: 150 plants $/ \mathrm{m}^{2}$ ) and high (HD; target: 250 plants $/ \mathrm{m}^{2}$ ) plant density treatment.

In 2013, wheat was hand-sown in autumn (21/05) into raised beds located in a netted enclosure at Black Mountain, Canberra. Levels of photosynthetically active radiation were $13 \%$ lower in the enclosure than outside. The soil in the raised beds $(0.2 \mathrm{~m}$ height) consisted $60 \%$ of a compost-based potting mix and $40 \%$ loam. Nutrients were supplied in the soil mix at rates of about $17 \mathrm{~kg} \mathrm{~N} / \mathrm{ha}, 8 \mathrm{~kg} \mathrm{P} / \mathrm{ha}$, and $6 \mathrm{~kg} \mathrm{~K} / \mathrm{ha}$. Raised beds were formed 1 week before sowing over soil. The lines were sown at $0.05 \mathrm{~m}$ depth, and $0.2 \mathrm{~m}$ between-row and $0.04 \mathrm{~m}$ withinrow spacing. When plants had three leaves, any gaps in the stand were filled by replanting individuals of identical phenological age. Thus, each line grew at a uniform density of 125 plants $/ \mathrm{m}^{2}$. Irrigation was applied up to flowering to avoid water-stress (22/05: $10 \mathrm{~mm}$; 12/07: $50 \mathrm{~mm}$; 11/09: $10 \mathrm{~mm}$; 25/09: $5 \mathrm{~mm} ; 5 / 10: 10 \mathrm{~mm})$. Fertilizer $\mathrm{N}$ was applied at rates of 30 (12/07), 20 (29/07), and 40 (23/08) kg N/ha. Fungicide was applied as required. The size of individual plots was $2.2 \mathrm{~m}^{2}$. There were two replications per line in a completely randomized design.

\section{SAMPLING}

The minimum width of the border excluded from sampling was $0.4 \mathrm{~m}$ in 2012 and $0.2 \mathrm{~m}$ in 2013. In 2012, plant establishment was assessed for each plot by counting plants in $1 \mathrm{~m}$ row when plants had about 3-4 leaves, while 125 plants $/ \mathrm{m}^{2}$ were established in 2013 as described above. At crop maturity, three rows of $0.4 \mathrm{~m}$ length were sampled to assess the number of spikes $/ \mathrm{m}^{2}$, and the average height of the crop stand was measured.

\section{PHENOLOGY AND TILLER IDENTIFICATION}

The Zadoks et al. (1974) decimal code (Z-score) for growth stages of cereals was adopted to record leaf numbers, inflorescence emergence (Z49-Z59), anthesis (Z60-Z69), and the start of seed filling (Z70). For example, a leaf Z-score of Z13 indicated three unfolded, mature leaves on a shoot, and Z13.5 indicated three unfolded, mature leaves with the size of the emerging fourth leaf being $50 \%$ of that of the third leaf. The emergence of the inflorescence was scored with Z49 indicating "first awns visible," Z55 " $50 \%$ of inflorescence emerged," and Z59 "emergence of inflorescence completed." The anthesis score Z60 indicated "start of anthesis" (i.e., anthers released on about $5 \%$ of spikes in a plot), and Z65 "anthesis half-way" (i.e., anthers released on $50 \%$ of spikes in a plot).

Tillers were identified with reference to the leaf, prophyll, or coleoptile axil in which they appeared (Klepper et al., 1983; Kirby and Appleyard, 1987; Bos and Neuteboom, 1998). Briefly, tillers growing from the main shoot (MS) are primary tillers, and those growing from primary tillers are secondary tillers, etc. The 1st (2nd, 3rd, etc.) primary tiller emerging from the leaf axil of the 1st (2nd, 3rd, etc.) leaf of the main shoots is identified as T1 (T2, $\mathrm{T} 2$, etc.). The secondary tiller emerging from the leaf axil of the 1st leaf of T1 (T2, T3, etc.) is labeled T1.1 (T2.1, T3.1, etc.). The coleoptile tiller is named T0. Secondary tillers emerging from the prophyll (modified leaf similar to the coleoptile) of a parent shoot are named T1.0, T2.0, etc. (Figure 1).

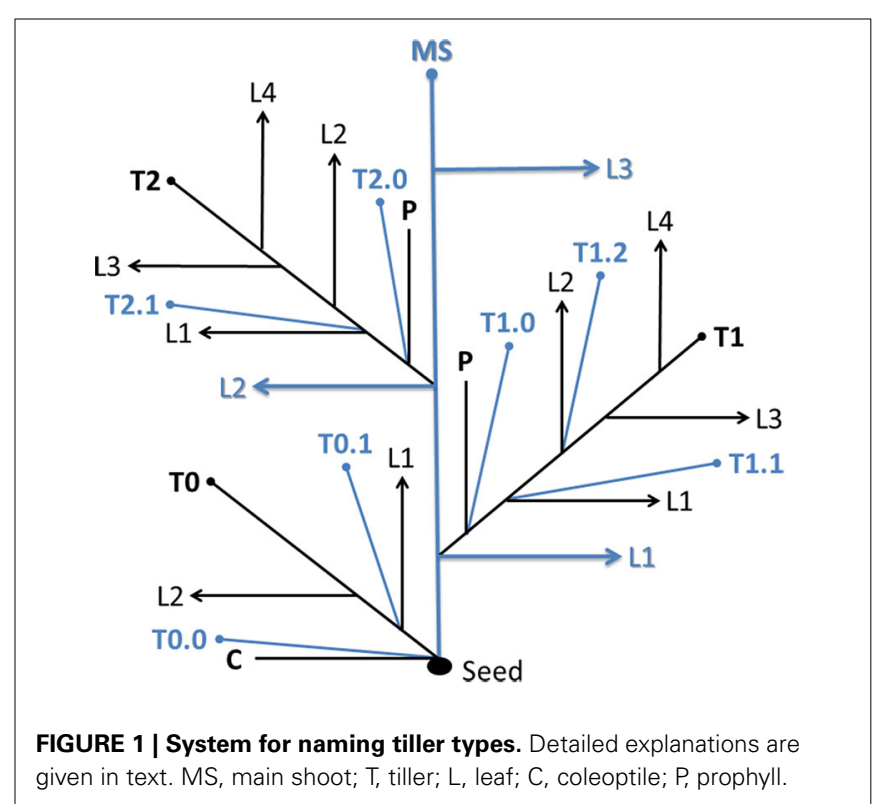


To identify tiller presence, plants were sampled two times in $2012(22 / 10$ and 23/10; $n=10$ plants) and three times in 2013 $(13 / 09,05 / 10$, and $23 / 10 ; n=20-25$ plants). At each occasion, the presence of a specific tiller (alive and senescing) was noted. In 2013 , changes in shoot number over time were monitored on an area basis (two adjacent rows with eight plants each) by counting the number of green shoots on the same plants every week up until the end of stem elongation.

\section{ORGAN SIZES}

The sizes of fully grown plant organs (width and length of leaf blades, length of leaf sheaths, internode and peduncle length) were estimated for each phytomer and shoot type (i.e., MS, $\mathrm{T} 1, \mathrm{~T} 2$, etc.). A phytomer consists of an internode, a node above the internode, a sheath growing from the node, and a leaf blade (Forster et al., 2007; Vos et al., 2010). Phytomers are counted acropetally on each shoot type. For example, the 8th leaf of the MS (T1, T2, etc.) belongs to phytomer eight of that shoot.

To estimate organ sizes, destructive samples were taken two times in $2012(22 / 10$ and 28/11) and three times in $2013(13 / 08$, $15 / 09$, and 23/10). On each occasion in 2012, 3-4 plants were collected at random from all plot per treatment. In 2013, 6-8 plants were sampled at random from two plots per treatment. The internode length data were used to calculate the phytomer shift values for each shoot type and derive the relative phytomer number (RPN; Evers et al., 2005; Vos et al., 2010). To obtain the RPN, a phytomer shift value, which is characteristic for each tiller, is added to the phytomer number (PN), the result is the superposition of tiller and main shoot data. The shift value for the main shoot is zero $(\mathrm{RPN}=\mathrm{PN})$. The shift values for each tiller type were calculated by simultaneously (i) fitting a linear regression model to the data of main shoot internode length data vs. PN, and (ii) minimizing the distance between the tiller internode data and the linear model. This was done by finding values for the tiller shifts and the parameters of the linear model such that the root-mean-squared error (RMSE) was minimized using the solver add-in of Microsoft Excel 2010. The frequency of occurrence of higher-order tillers was commonly low resulting in low numbers of replications $(n=1-2)$. In these cases the data were excluded from the analysis.

\section{GREEN LEAF AREA}

To estimate the Leaf Area Index (LAI; leaf area per unit ground area), the area of green leaf blades was measured with a leaf area meter (Delta-T-Devices Ltd., Burwell, UK). In 2012, samples were taken at anthesis (25/11) from $0.4 \mathrm{~m}^{2}$ of which a subsample of 10 plants was used to determine LAI. In 2013, to obtain a better understanding of the vertical distribution of leaf area, stratified cuts were taken in-situ at the start of spike emergence (19-30/09) and at flowering (15-18/10). At each occasion, $2 \times 8$ plants $\left(0.13 \mathrm{~m}^{2}\right)$ per plot were sampled. Stratified clips were taken at $0-0.15 \mathrm{~m}$ (ground-level), $0.15-0.3 \mathrm{~m}$, $0.30-0.45 \mathrm{~m}, 0.45-0.6 \mathrm{~m}, 0.6-0.75 \mathrm{~m}$, and, depending on final canopy height, $0.75-0.9 \mathrm{~m}$ to estimate the LAI for each canopy layer.

\section{GROUND-COVER}

The percentage ground-cover (GC\%) was estimated from digital camera photos taken during tillering. The software Canopy Cover was used to convert green pixels into GC\% (Li et al., 2010).

\section{LIGHT INTERCEPTION}

Levels of Photosynthetic Active Radiation (PAR, $\mu \mathrm{mol} / \mathrm{m}^{2} / \mathrm{s}$ ) above $\left(\mathrm{I}_{0}\right)$ and below $\left(\mathrm{I}_{1}\right)$ the crop canopy $(0-0.05 \mathrm{~m}$ above ground-level) were measured within $3 \mathrm{~h}$ around noon using a ceptometer (AccuPAR PAR-80, Decagon Devices Inc., Pullman WA, US). The data were used to estimate the percentage PAR $(\mathrm{PAR} \%=$ $\left.\mathrm{I}_{1} / \mathrm{I}_{0} \times 100\right)$ and the percentage intercepted PAR (IPAR $\%=\mathrm{I}_{0}-$ $\left.\mathrm{I}_{1} / \mathrm{I}_{0} \times 100\right)$. Measurements were taken up until anthesis; five times in 2012 and 17 times in 2013. In 2013, stratified measurements of PAR (two replications per treatment) were taken six times between the appearance of the flag leave and the start of seed-filling.

To relate light interception to leaf area, stratified measurements were taken at the same heights as for the estimation of LAI: 0-0.15 m, 0.15-0.3 m, 0.30-0.45 m, 0.45-0.6 m, 0.6-0.75 m, 0.75$0.9 \mathrm{~m}$, and above the canopy. To describe the light interception characteristics of NILs differing in tin, Monsi and Saeki's (1953) modified version of the Lambert-Beer law was used:

$$
\mathrm{I}_{1}=\mathrm{I}_{0} \times \exp \left(-k \times \mathrm{LAI}_{1}\right)
$$

Where $I_{1}$ is the radiation received at a specific canopy height, $I_{0}$ is the incident PAR\% (typically 100\%), $k$ is the light extinction coefficient of the canopy, and $\mathrm{LAI}_{1}$ is the leaf area index at the height of $\mathrm{I}_{1}$.

\section{RED TO FAR-RED RATIO}

In 2013, R:FR was measured at around noon at the plant base between tillering (weekly measurements) and the start of flowering using a Skye SKR100/116 fiber optic probe with diffuser (Skye Instruments Ltd, Llandrindod Wells, UK). The sensor with diffuser accepts light from $180^{\circ}$ hemisphere, while a narrower field of view of $80^{\circ}$ hemisphere is measured by sensors without diffuser (e.g., Evers et al., 2006). During the measurements, the sensor faced away from the sun (south in the southern hemisphere), and parallel to the soil surface and green shoot structures. At each occasion, five measurements were taken in each treatment.

\section{CHLOROPHYLL STATUS}

A chlorophyll meter (SPAD 502, Spectrum Technologies Inc., Aurora, IL, US) was used to estimate the leaf chlorophyll status (Chl). Measurements were taken about $40 \mathrm{~mm}$ from the leaf tip on 4-6 leaves of the same physiological age. In the 2012, measurements were taken on flag leaves of main shoots and subjacent 4th leaves on 14/11 (flag leaves fully expanded). In 2013, Chl was measured on 13-17/09 ( $\mathrm{mid} /$ late booting stage), 05/10 ( start of anthesis) and 23/10 (seed-filling) on flag leaves and all subjacent alive leaves on main shoots and primary tillers T1 and $\mathrm{T} 2$. 


\section{WEATHER DATA AND CALCULATIONS}

Daily minimum and maximum temperatures $\left({ }^{\circ} \mathrm{C}\right)$, and solar radiation $\left(\mathrm{MJ} \mathrm{m}^{2} /\right.$ day) were sourced from the Ginninderra experiment station $\left(35.20^{\circ} \mathrm{S}, 149.08^{\circ} \mathrm{E}, 600 \mathrm{~m}\right.$ a.s.l). The weather station was located close to the experiment in 2012, and about $6 \mathrm{~km}$ from the Black Mountain site used in 2013. In 2013, netting of the enclosure reduced radiation by $13 \%$ and the solar radiation data were adjusted accordingly. Daily rainfall $(\mathrm{mm})$ data were recorded close to the experiments.

Cumulative thermal time (cTT in degree days, ${ }^{\circ} \mathrm{Cd}$ ) was calculated from emergence as

$$
\mathrm{cTT}\left({ }^{\circ} \mathrm{Cd}\right)=\sum_{i=1}^{\mathrm{n}}\left(\mathrm{T}_{\max }+\mathrm{T}_{\text {min_b }}\right) / 2
$$

Where $T_{\max }$ is the mean maximum temperature, $T_{\min \_b}$ is the mean minimum temperature adjusted for a base temperature at which development is thought to stop, and $n$ is the number of days of temperature observations used in the summation (Ritchie and $\mathrm{NeSmith}, 1991)$. The base temperature was $0.0^{\circ} \mathrm{C}$, i.e., if the mean minimum temperature was lower than the base temperature the consequent value of $\mathrm{T}_{\min \_\mathrm{b}}$ was zero on that day (Ritchie, 1991). The phyllochron, defined as the thermal time interval between the appearances of successive leaves on a shoot, was obtained as the slope of the linear regression of cTT against the number of leaves with the intercept set to zero.

\section{DATA ANALYSIS}

Seasons were analyzed separately in GenStat (16th Edition, VSN International, Hemel Hempstead, UK). For the analysis of the 2012 data (except organ sizes and tiller types), mixed models were fitted using ASREML. The best spatial model was determined statistically after sequential model fitting and included the factors of the experimental design ("environment," "genotype," and "plant density"). The residual variation was modeled with autoregressive (AR1) row and column terms, and fitting of a linear row term (all effects statistically different from zero at $p=0.05$ ). The interaction and main effects of "environment" (irrigated and rain-fed) were non-significant $(p>0.70)$, and the effects were subsequently pooled with the residual. Other data were analyzed using the GLM procedure in GenStat. The 2012 (factors: "genotype" and "density") and 2013 (factor: "genotype") data on presence/absence of tiller types were transformed using an arcsine square root transformation before the statistical analysis.

\section{RESULTS}

\section{SEASONAL CONDITIONS AND PHENOLOGY}

Contrasting photo-thermal conditions and levels of water supply (Figure 2) resulted in lifecycle durations of only $\sim 90$ days in 2012 but $\sim 180$ days in 2013, i.e., plant development was hastened in 2012 compared to 2013. In 2012, late-sown wheat experienced increasing day lengths and temperatures from emergence onward. In-crop water supply (rainfall plus irrigation from sowing until maturity) was $200 \mathrm{~mm}$ only, and symptoms of waterstress became apparent from around tillering onward. In contrast, day-lengths and temperatures decreased initially in 2013, and incrop water supply was $475 \mathrm{~mm}$. Tillering commenced at $229^{\circ} \mathrm{Cd}$

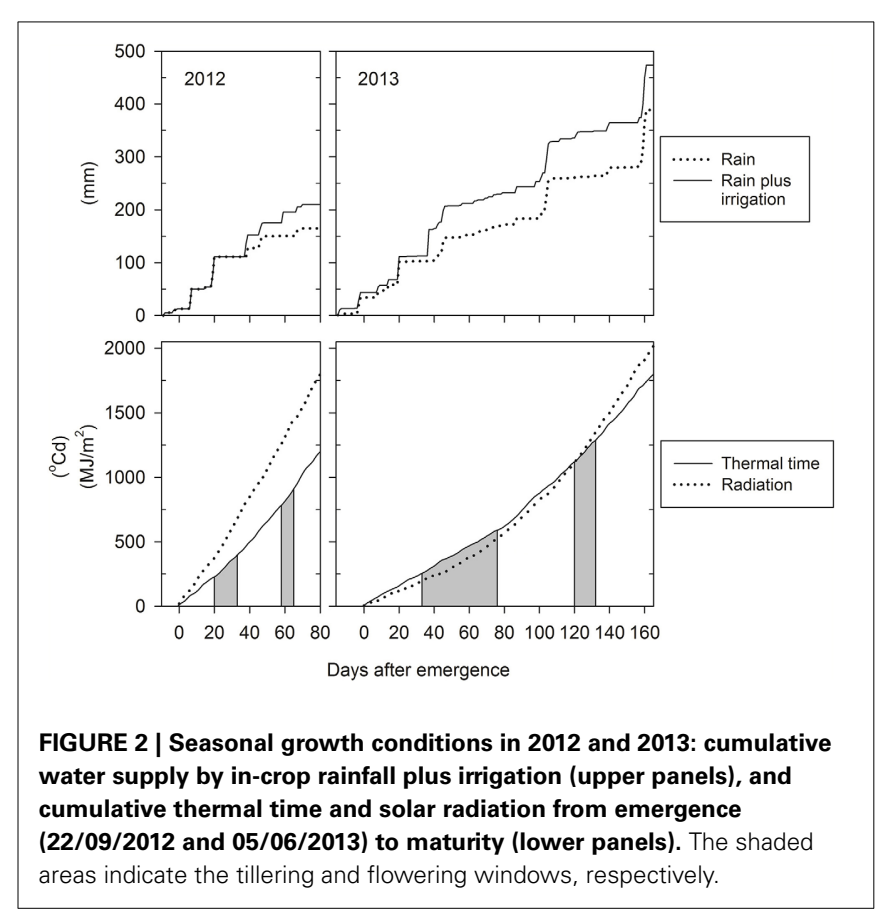

(20 days after emergence, DAE) in 2012 and at $256^{\circ} \mathrm{Cd}(33 \mathrm{DAE})$ in 2013. Anthesis commenced earlier in 2012 compared to 2013 both in terms of the number of days required from emergence to start of anthesis (61 vs. $122 \mathrm{DAE}$ ) and the average amount of thermal units accumulated over this period ( 826 vs. $\left.1143^{\circ} \mathrm{Cd}\right)$. Each near-isogenic pair had similar anthesis dates (Table 1), which is important for any comparisons to be unconfounded by differences in phenology. The pair $7770 / 7770_{\text {tin }}$ flowered 3-5 days earlier than the pair $\mathrm{B} / \mathrm{B}_{\text {tin }}$ consistent with the earlier maturity of the parental donor Wyalkatchem (Table 1). Across genotypes, the average phyllochron was $76^{\circ} \mathrm{Cd}$ in 2012 and $87^{\circ} \mathrm{Cd}$ in 2013 , which corresponds to a difference in leaf appearance rate of about 1 day. Some of this difference could be related to the source of temperature data as described above. However, the faster leaf appearance in 2012 is in line with an overall hastened plant development in this short season, where plants produced about two main stems leaves less compared to 2013 (Table 1).

\section{ARCHITECTURAL ATTRIBUTES: ORGAN SIZES}

In each genotype, the distribution of organ sizes along a shoot (i.e., the gradual changes in blade width and length, sheath length, and internode length with phytomer number) was similar for main shoots and tillers. This can be demonstrated by applying the concept of Relative Phytomer Number (RPN; Figure 3). For example, the RPN for $\mathrm{T} 1$ of line $\mathrm{B}_{\text {tin }}$ was " $\mathrm{RPN}=$ phytomer number +1.81 " and that for T2 was "RPN = phytomer number + 1.86" (RMSE = 15.6; Figure 3). These similarities were greater in 2013 (long season and minimal moisture stress) compared to 2012 (short season and severe water-stress) (data not shown). Because of the architectural similarities between main shoots and tillers, only MS data are presented in the following sections.

The distribution of leaf sizes along the main shoot varied between tin and non-tin genotypes in both seasons (Figures 4, 5). 
Table 1 | Estimated date of start of anthesis (Z60), days after emergence (DAE) to Z60, cumulative thermal time (cTT) from emergence to Z60, average maximum number of main shoot leaves (LN), and phyllochrons of main shoot leaves of near-isogenic wheat lines differing in the tin gene grown in two contrasting seasons at Canberra.

\begin{tabular}{|c|c|c|c|c|c|c|c|c|}
\hline $\begin{array}{l}\text { Line } \\
\text { Season }\end{array}$ & \multicolumn{2}{|c|}{7770} & \multicolumn{2}{|c|}{$7770_{\text {tin }}$} & \multicolumn{2}{|c|}{ B } & \multicolumn{2}{|c|}{$\mathrm{B}_{\text {tin }}$} \\
\hline Anthesis $(Z 60)^{a}$ & 19/11 & $03 / 10$ & $19 / 11$ & $04 / 10$ & $24 / 11$ & $06 / 10$ & $24 / 11$ & $06 / 10$ \\
\hline DAE & 58 & 120 & 58 & 121 & 63 & 123 & 63 & 123 \\
\hline$r^{2}$ & 0.89 & 0.78 & 0.89 & 0.85 & 0.86 & 0.91 & 0.78 & 0.95 \\
\hline RMSE (days) & 1.5 & 3.9 & 1.6 & 2.6 & 1.6 & 2.6 & 1.4 & 1.9 \\
\hline LN & 8.1 & 9.9 & 8 & 10 & 8.3 & 10 & 8.5 & 10.1 \\
\hline s.e. & 0.22 & 0.07 & 0.0 & 0.0 & 0.14 & 0.07 & 0.16 & 0.07 \\
\hline Phyllochron $\left({ }^{\circ} \mathrm{Cd}\right)^{\mathrm{b}}$ & 77 & 85 & 73 & 85 & 79 & 90 & 75 & 86 \\
\hline$r^{2}$ & 0.90 & 0.95 & 0.87 & 0.95 & 0.93 & 0.95 & 0.94 & 0.95 \\
\hline RMSE & 44 & 62 & 45 & 60 & 36 & 62 & 36 & 63 \\
\hline
\end{tabular}

a Start of anthesis (Z60) date $=a \times$ date $+b$; linear regression of observed Z-scores (Z50-Z70) against date.

${ }^{b} \mathrm{CTT}=a \times L N$, with a corresponding to the phyllochron.
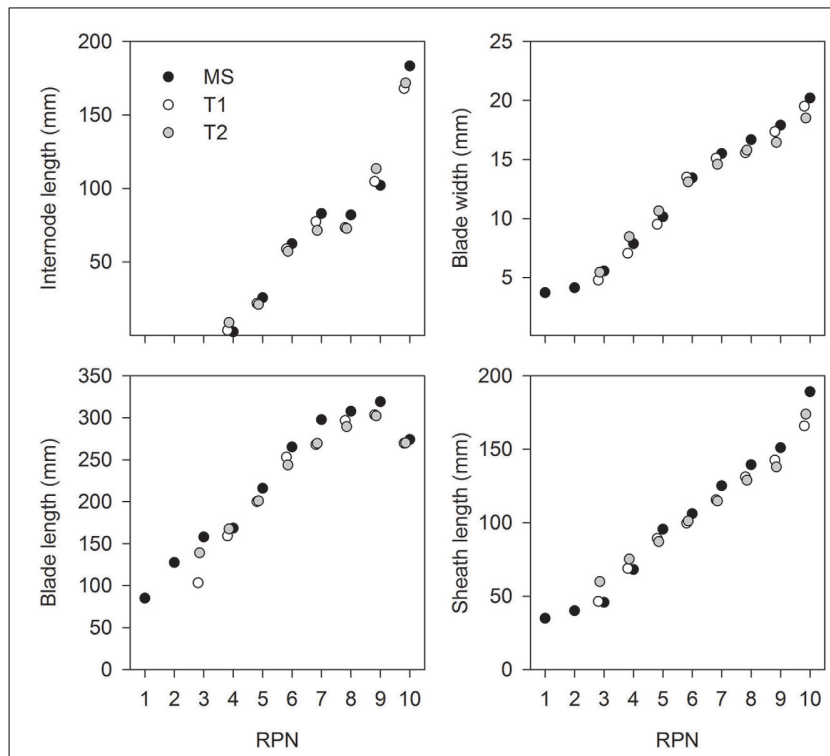

FIGURE 3 | Average size of plant organs against relative phytomer number (RPN) for the main shoot (MS) and primary tillers T1 and T2 of line $B_{\text {tin }}$ grown at Canberra, 2013.

The main features were the larger flag leaves of tin lines, and that the longest leaf blades were observed at lower phytomers in the free-tillering lines compared to the tin lines (Figures 4, 5).

In 2012, organ sizes were similar at both plant densities $(p>$ $0.60)$ despite significant differences between densities in the number of plants at establishment $(p<0.001)$, and the number of shoots measured at flag leaf expansion $(p=0.023)$. Thus, the effect of density on organ sizes was pooled with the residual variation. More specifically, the length of flag leaves was 105 and $139 \mathrm{~mm}$ in lines 7770 and $7770_{\text {tin }}$, and 130 and $159 \mathrm{~mm}$ in lines B and $\mathrm{B}_{\text {tin }}(p<0.001, \mathrm{LSD}=20)$. The width of flag leaf blades was 12.5 and $15 \mathrm{~mm}$ in lines 7770 and $7770_{\text {tin }}$, and about $13 \mathrm{~mm}$ in B and $\mathrm{B}_{\text {tin }}(p<0.001, \mathrm{LSD}=1.1)$. Similarly, the penultimate leaf was larger in the tin lines for both blade width $(p<0.001, \mathrm{LSD}=$ $0.8)$ and length $(p<0.001, \mathrm{LSD}=19)$. The longest leaf blades were observed at about phytomer five in 2012 . Here, leaf blades were significantly longer in the free-tillering compared to the tin lines $(p<0.001$, LSD $=17)$, while the blade widths were similar $(p=0.16)$ (Figures 4, 5).

In 2013, the length of flag leaf blades was 217 and $247 \mathrm{~mm}$ in lines 7770 and $7770_{\text {tin }}$, and 224 and $274 \mathrm{~mm}$ in lines $\mathrm{B}$ and $\mathrm{B}_{\text {tin }}$ $(p<0.001$, LSD $=26)$, while there were no differences in flag leaf width, which was about $20 \mathrm{~mm}$ in all lines $(p=0.2)$. There was a significant effect of genotype on the width $(p=0.017$, LSD $=$ $1.12)$ and length $(p=0.006, \mathrm{LSD}=25)$ of the penultimate leaf though this was unrelated to the presence or absence of the tin gene. Similar to the 2012 season, the longest leaf blades were observed at lower phytomers in free-tillering lines compared to the tin lines (7-8 vs. 9). At phytomer eight, for example, leaf blades were significantly longer in the free-tillering lines $(p<$ 0.001 , LSD $=18)$ while leaf blades were wider in the tin lines $(p=0.039, \mathrm{LSD}=1)$ (Figures 4, 5).

The pattern of fully elongated internodes varied between tin and non-tin genotypes (Figure 6). For example, internode elongation commenced at a lower phytomer in the tin lines. In 2012, the 1st and 2 nd basal internode did not elongate in any line while the final length of the 3 rd basal internode (phytomer 3 ) was $3 \mathrm{~mm}$ in line $7770_{\text {tin }}$ and $5 \mathrm{~mm}$ in line $\mathrm{B}_{\text {tin }}$ but $1 \mathrm{~mm}$ in the freetillering NILs $(p<0.001, \mathrm{LSD}=2)$. In 2013 , the 1 st, 2 nd, and 3rd basal internode did not elongate in any line. The final length of the 4 th internode (phytomer 4 ) was $2.5 \mathrm{~mm}$ in line $\mathrm{B}_{\text {tin }}$ and $1 \mathrm{~mm}$ line $\mathrm{B}$, and about similar in the pair $7770_{\text {tin }}$ and $7770(1.3$ vs. $1 \mathrm{~mm} ; p=0.01, \mathrm{LSD}=0.6$ ).

The peduncle and the internode below the peduncle tended to be shorter in the tin compared to the free-tillering lines 


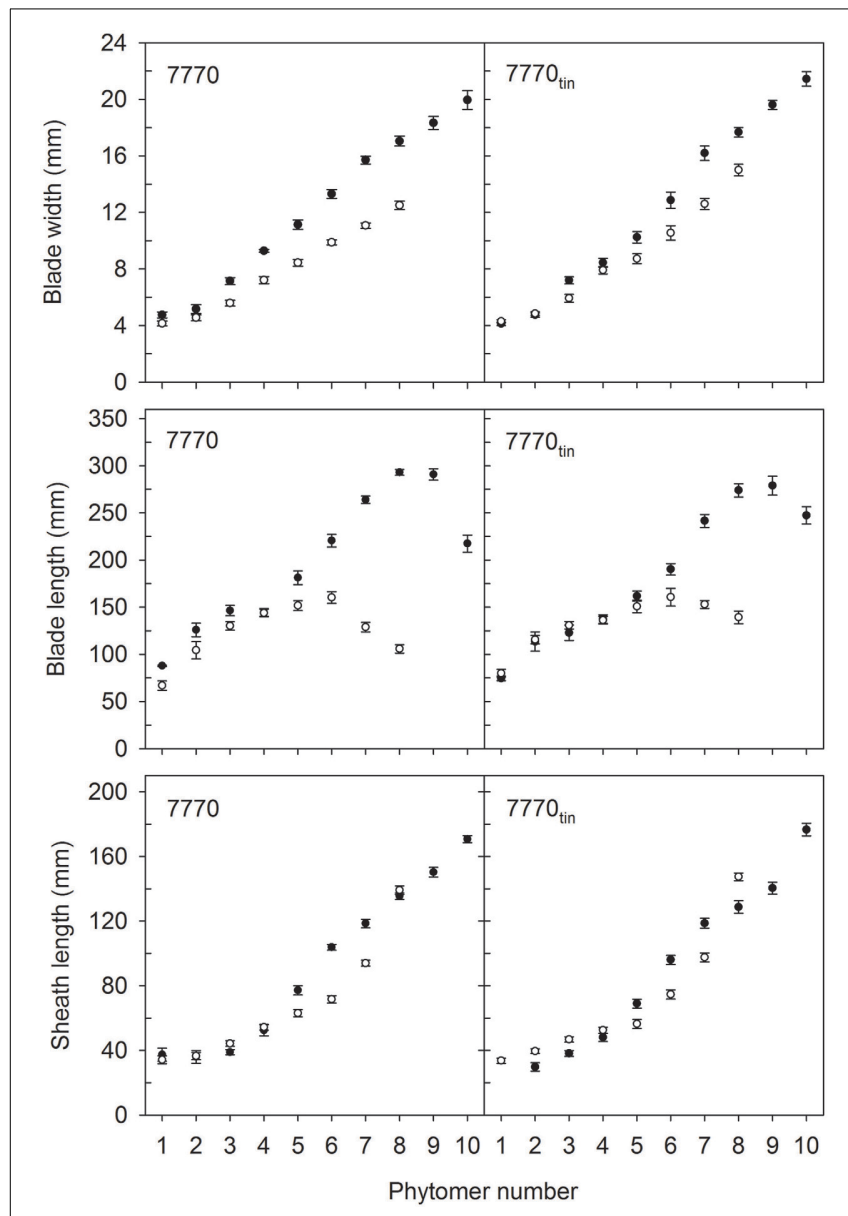

FIGURE 4 | Characteristics of main shoot leaves in lines 7770 and $\mathbf{7 7 7 0}_{\text {tin }}$, which are near-isogenic for the tin gene, grown in 2012 (white symbols) and 2013 (black symbols) at Canberra. Error bars show \pm one standard error. Only data of plants with seven (2012) and 10 main shoot phytomers (2013) are shown.

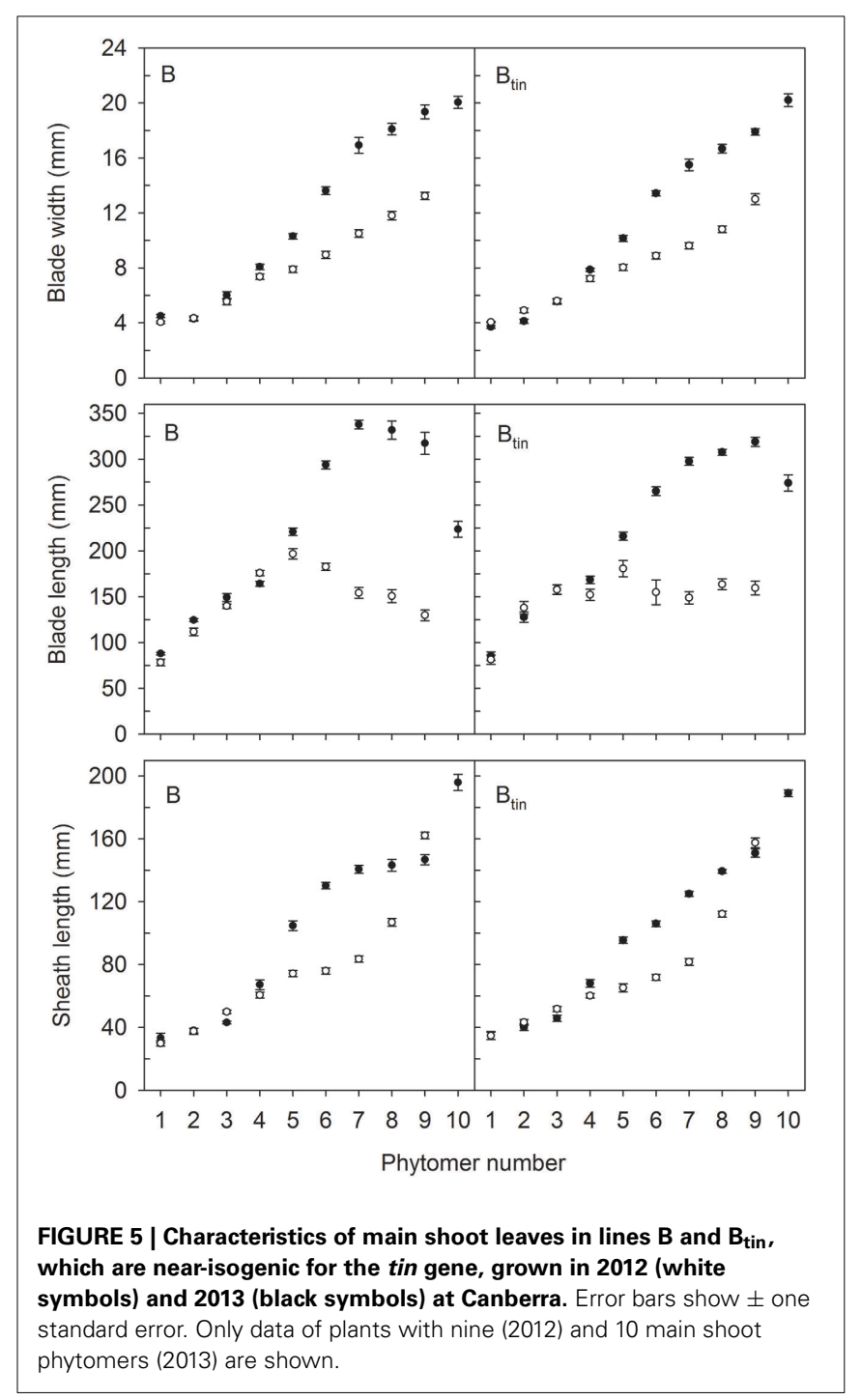

\section{SHOOTS AND SPIKES}

Overall, the tin lines produced fewer shoots and spikes compared to their free-tillering sisters in both seasons (Figures 7, 8). In 2012, the target plant densities were closely realized with 242 plants $/ \mathrm{m}^{2}$ in the HD, and 141 plants $/ \mathrm{m}^{2}$ in the LD treatment $(p<0.001, \mathrm{LSD}=11)$. Across densities, plant establishment was 192-196 plants $/ \mathrm{m}^{2}$ except in line $\mathrm{B}_{\text {tin }}$ were early establishment was 171 plants $/ \mathrm{m}^{2}(p<0.001, \mathrm{LSD}=17)$. The effect of density carried through until maturity and was significant for the number of shoots counted at 54 DAE, corresponding with the expansion of flag leaves (504 shoots $/ \mathrm{m}^{2}$ in the HD, and 415 shoots $/ \mathrm{m}^{2}$ in the LD treatment; $p=0.023, \mathrm{LSD}=65$ ), and spike number (123 spikes $/ \mathrm{m}^{2}$ in the HD, and 95 spikes $/ \mathrm{m}^{2}$ in the LD treatment; $p<0.001, \mathrm{LSD}=10.4$ ). Around 30-50\% fewer spikes than plants at establishment indicated that a number of plants died or did not produce a spike in this short and water-limited season. There was a significant effect of genotype on shoot $(p=0.006, \mathrm{LSD}=$ $127)$ and spike number $(p<0.001, \mathrm{LSD}=11)$. At $54 \mathrm{DAE}$, the tin lines had $30-35 \%$ fewer shoots, i.e., 7770 and $7770_{\text {tin }}$ had 501 and 363 shoots $/ \mathrm{m}^{2}$, and $\mathrm{B}$ and $\mathrm{B}_{\text {tin }}$ had 514 and 338 shoots $/ \mathrm{m}^{2}$, 


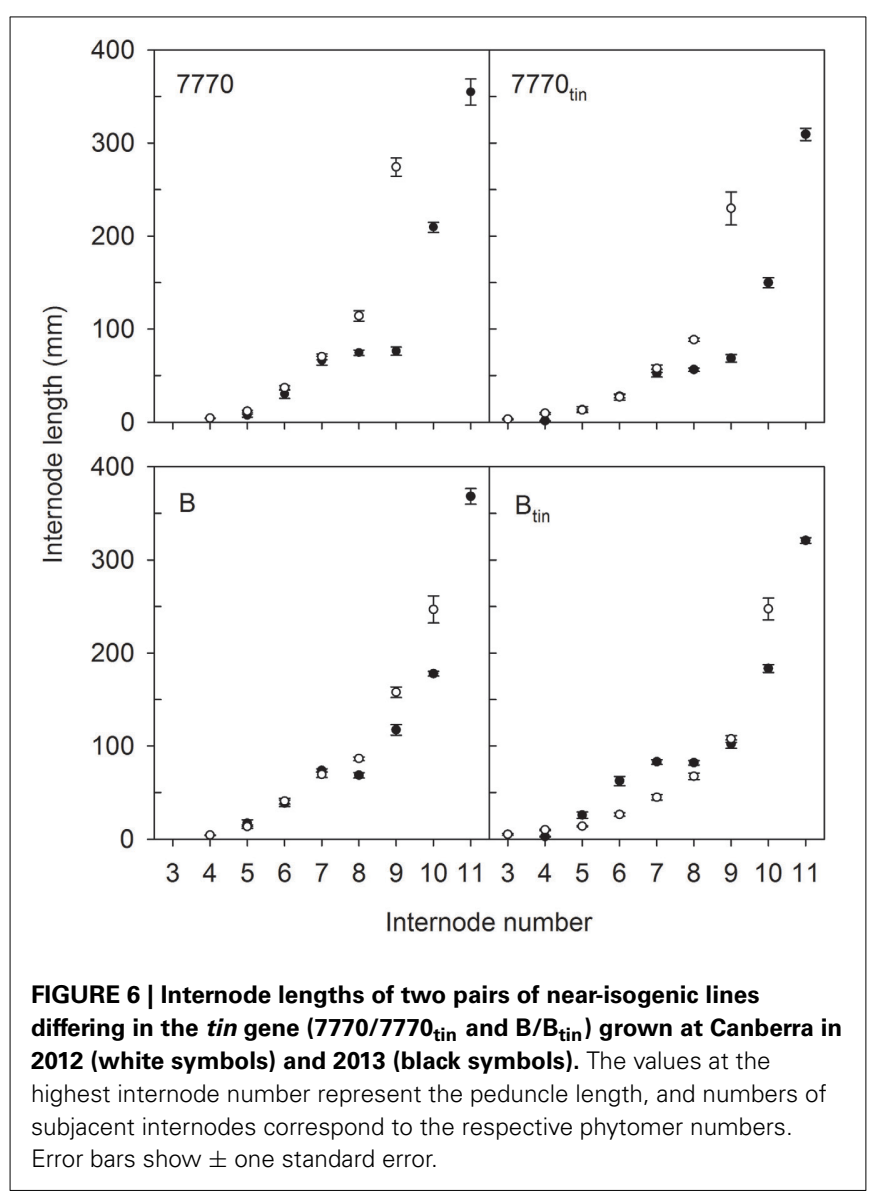

respectively. Spike number was reduced by $16 \%$ in line $7770_{\text {tin }}$ compared to 7770 (106 vs. 127 spikes $/ \mathrm{m}^{2}$ ) and by $40 \%$ in $\mathrm{B}_{\text {tin }}$ compared to B (76 vs. 126 spikes $/ \mathrm{m}^{2}$ ).

In 2013, when plant establishment was exactly 125 plants $/ \mathrm{m}^{2}$, the maximum shoot number was $30 \%$ less in line $7770_{\text {tin }}$ compared to 7770 ( 531 vs. 759 shoots $/ \mathrm{m}^{2}$ ), and $40 \%$ less in line $\mathrm{B}_{\text {tin }}$ compared to $\mathrm{B}\left(494\right.$ vs. 861 shoots $\left./ \mathrm{m}^{2}\right)(p<0.001, \mathrm{LSD}=$ 62 ). Tillering ceased about 12 days earlier in the tin lines compared to the free-tillering sisters with the maximum number of shoots being measured at $64 \operatorname{DAE}(08 / 08)$ in the tin, and at 76 DAE (20/08) in the free-tillering lines (Figure 7). At maturity, spike number was $20 \%$ reduced in line $7770_{\text {tin }}$ compared to 7770 (387 vs. 478 spikes $/ \mathrm{m}^{2}$ ) and $30 \%$ reduced in $\mathrm{B}_{\text {tin }}$ compared to B (376 vs. 537 spikes $\left./ \mathrm{m}^{2}\right)(p<0.001, \mathrm{LSD}=69)$. Continuous monitoring of changes in shoots numbers over time (Figure 7) allowed for the calculation of the tiller economy, which was significantly greater in the tin lines $\left(7770_{\text {tin }}: 0.73 ; \mathrm{B}_{\mathrm{tin}}: 0.76\right)$ than in the free-tillering lines (7770: 0.63; B: 0.62), i.e., more tillers became reproductive shoots in the tin lines.

On a per plant basis, reduced tillering plasticity of tin genotypes was indicated by lower frequencies of later primary tillers (e.g., T3, T4) and secondary tillers (e.g., T1.1, T2.1), which ultimately resulted in lower numbers of tillers per plant in comparison to the free-tillering lines, especially under favorable growth conditions in 2013 (Figure 8). Note that the shoot numbers per plant derived from Figure 8 and Figure 7 vary slightly due to the sampling differences described above. Generally, primary tillers T1 and T2 were observed most frequently followed by T3 (Figure 8). The coleoptile tiller (T0) was observed almost exclusively in 2013 with a mean frequency of 0.2 in free-tillering and 0.06 in tin lines (data not shown). In 2012, all lines responded to increased plant density by reducing the numbers of later tillers. There were genotypic differences in the presence of T1 and T2 $(p=0.014)$, while the presence of T3 was influenced by both genotype $(p=0.011)$ and plant density $(p<0.001)$. Across densities, lines 7770 and $7770_{\text {tin }}$ produced on average about one T1 and $0.85 \mathrm{~T} 2$, line $\mathrm{B}$ had $0.85 \mathrm{~T} 1$ and $0.6 \mathrm{~T} 2$, and $\mathrm{B}_{\text {tin }}$ produced $0.37 \mathrm{~T} 1$ and $\mathrm{T} 2$ per plant. Overall, T3 appeared more frequently in the free-tillering compared to the tin lines. At HD, tiller T3 was either absent, as in line B and both tin genotypes, or present in small numbers as in line 7770 ( 0.18 vs. 0.84 at LD) (Figure 8). In 2013, all lines had an average of $\sim$ one $\mathrm{T} 1$ and T2, and genotypic differences were only evident in the numbers of secondary and higher order primary tillers (Figure 8). The free-tillering lines had on average around $0.9 \mathrm{~T} 3$ and the tin lines $0.15 \mathrm{~T} 3$ per plant $(p<0.001)$. Tillers T4 and T5 were mostly absent in the tin lines while the free-tillering lines produced about $0.5 \mathrm{~T} 4$ and $0.15 \mathrm{~T} 5$ $(p<0.001)$.

\section{LIGHT INTERCEPTION, RED: FAR-RED RATIO, AND CHLOROPHYLL CONTENT}

The tin lines intercepted less radiation compared to the freetillering lines, and this difference was generally significant throughout both seasons $(p \leq 0.05)$ (Figures 7, 9). In 2012, the effect of plant density on IPAR\% was mostly significant $(p<$ $0.001)$. The IPAR\% was greater at $\mathrm{HD}$ than at $\mathrm{LD}$, expect for the last measurement taken during seed-filling (72 DAE). The decline of IPAR\% at 72 DAE in all treatment combinations can be explained by the collapsing of leaves in the rapidly senescing, water-stressed crop (Figure 9). Differences in canopy development between NILs were associated with consistently lower light interception and groundcover (GC\%) in tin lines compared to the free-tillering lines. For example, lines 7770 and $7770_{\text {tin }}$ intercepted $19 \%$ and $14 \%$ IPAR\%, and lines B and $B_{\text {tin }}$ intercepted 22 and $12 \% \operatorname{IPAR} \%$ during tillering at $32 \mathrm{DAE}(p=0.004, \mathrm{LSD}=$ 4.6). At this stage, GC\% was 33 and $22 \%$ in the tin lines $7770_{\text {tin }}$ and $\mathrm{B}_{\text {tin }}$ but around $40 \%$ in the free-tillering sisters $(p<0.001$, LSD = 3.6).

Under favorable growth conditions in 2013, light interception was reduced in tin lines compared to the free-tillering sisters from late tillering until maximum canopy expansion. Thus, light penetrated deeper into the canopies of tin lines and hence R:FR measured at the plant base was generally greater in tin compared to non-tin lines (Figure 7). At 70 DAE during tillering, IPAR\% was $56 \%$ in the tin lines and $62-63 \%$ in the free-tillering sisters $(p<0.001, \mathrm{LSD}=4.1)$. Reduced light interception in tin lines can be explained by their smaller canopies as indicated by fewer tillers (Figure 7) and reduced GC\%, which was 73-74\% in the tin lines and $81-82 \%$ in the free-tillering lines during tillering at 70 DAE $(p<0.001, \mathrm{LSD}=0.9)$. At 106 DAE, when flag leaves were fully expanded, the IPAR\% was $96 \%$ in the tin lines and $99 \%$ the free-tillering lines $(p<0.001, \mathrm{LSD}=1.3)$ (Figure 7).

The maximum tiller numbers were observed at 64 DAE in the tin lines and at $76 \mathrm{DAE}$ in the free-tillering lines (Figure 7). At this stage, both R:FR and PAR\% measured at ground-level were 

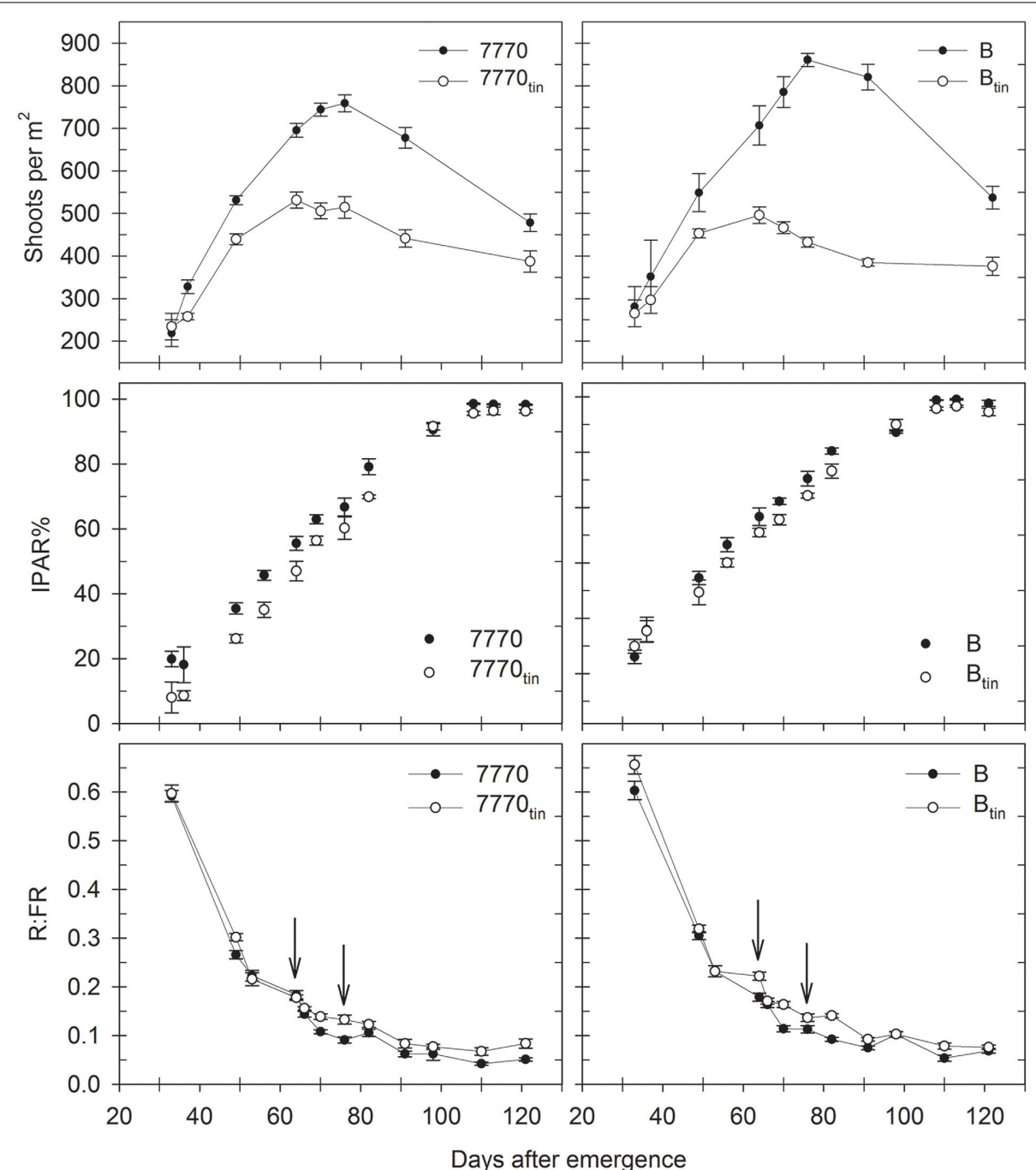

FIGURE 7 | Changes in shoot numbers, percentage of intercepted photosynthetic active radiation (IPAR\%), and red: far-red ratio (R:FR) in two pairs of near-isogenic lines differing in the tin gene $\left(7770 / 7770_{\text {tin }}\right.$ and $\mathbf{B} / \mathbf{B}_{\text {tin }}$ ) grown at Canberra in 2013. Arrows indicate $R: F R$ at maximum tiller number in tin (64 days after emergence) and free-tillering lines (76 days after emergence). Error bars show \pm one standard error. greater in the tin lines compared to the free-tillering sisters. The R:FR ratio at maximum tiller number was 0.18 and 0.09 in lines $7770_{\text {tin }}$ and 7770 , and 0.22 and 0.11 in lines $\mathrm{B}_{\text {tin }}$ and $\mathrm{B}(p<0.001$, LSD $=0.02$ ), and PAR $\%$ was $53 \%$ and $33 \%$ in lines $7770_{\text {tin }}$ and 7770 , and 49 and $30 \%$ in lines $\mathrm{B}_{\text {tin }}$ and $\mathrm{B}$, respectively $(p<0.001$, LSD $=8)$.

Generally, chlorophyll ( $\mathrm{Chl}$ ) measurements showed that the tin lines maintained the green area of lower leaves for longer into the season. In 2012, the Chl estimated at about 1 week before anthesis (53 DAE) on fully grown flag leaves and subjacent 4 th leaves was greater at LD compared to HD and greater in the tin compared to the free-tillering lines $(p<0.001)$. Across lines, the flag leaf $\mathrm{Chl}$ was 56.8 (SPAD units) at LD and 53.5 at HD (LSD $=2.3$ ), and Chl of the 4 th leaf from top was 50.3 at LD and 44.4 at HD (LSD $=3.7$ ). The $\mathrm{Chl}$ of flag leaves of lines 7770 and $7770_{\text {tin }}$ was 56.8 and 59 , and that of lines $B$ and $B_{\text {tin }}$ was 51.6 and 53 (LSD = 1.6). The 4th leaf from top had a Chl of 43.7 and 46.2 in lines 7770 and $7770_{\text {tin }}$, and 43.8 and 55.8 in lines $\mathrm{B}$ and $\mathrm{B}_{\text {tin }}(\mathrm{LSD}=2.6)$.
In 2013, changes in chlorophyll content with leaf age were monitored from full expansion of flag leaves ( $\mathrm{mid} / \mathrm{late}$ booting) until seed-filling (Figure 10). The flag leaves of tin lines had initially significantly higher Chl values $(p<0.001$, LSD $=$ 4.9) but this difference observed at 100-104 DAE (booting) disappeared as the flag leaves aged (Figure 10). Lower in the canopy, the Chl of the 6th leaf of the main shoot (phytomer six) of the tin lines was greater at 100-104 DAE $(p<0.001$, $\operatorname{LSD}=19)$ and $122 \operatorname{DAE}(p=0.024, \operatorname{LSD}=21.5)$ but leaf 6 had senesced at 140 DAE (low or zero Chl). At the start of flowering (122 DAE), the senescence of lower leaves was more advanced in the free-tillering lines compared to the tin lines (Figure 10). During seed-filling at $140 \mathrm{DAE}$, the Chl of leaves of tin and free-tillering lines were mostly similar except the Chl of leaf seven, which was greater in line $7770_{\text {tin }}$ compared to $7770(p=0.006$, LSD $=18.4)$. The leaf Chl of the primary tillers T1 and T2 resembled those of the main shoot (not shown). 


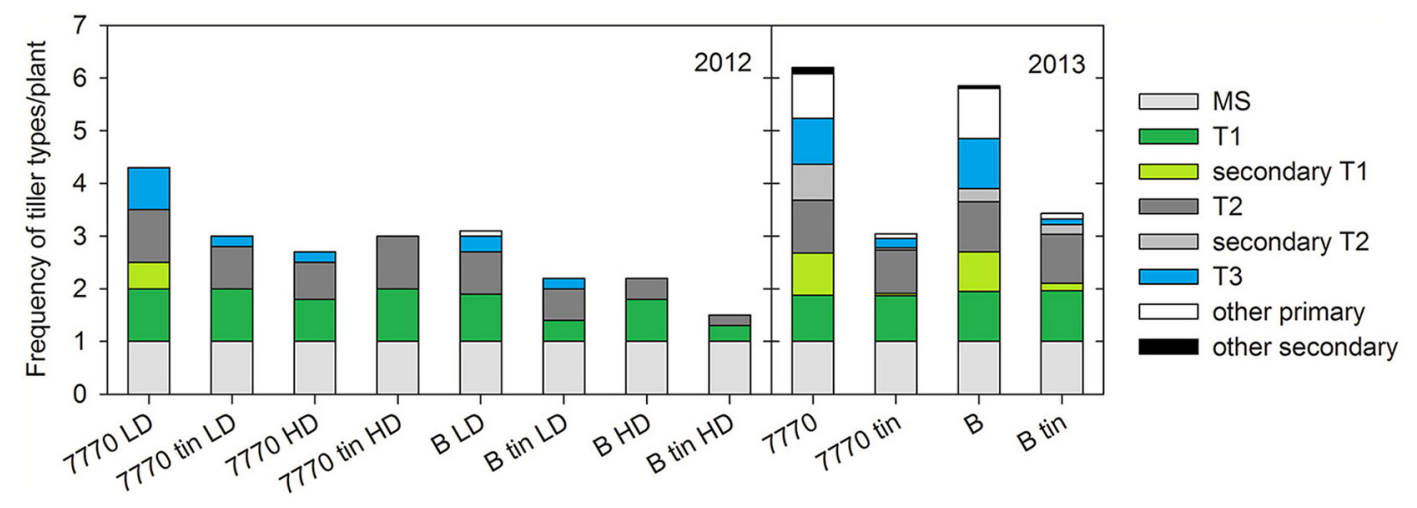

FIGURE 8 | Frequency of tiller types per plant in two pairs of near-isogenic lines differing in the tin gene $\left(7770 / 7770_{\text {tin }}\right.$ and $\left.B / B_{\text {tin }}\right)$ grown at Canberra at a high (HD) and low (LD) plant density in 2012, and one uniform density in 2013: main shoot (MS), 1st primary tiller (T1) and secondary tillers on T1, 2nd primary tiller (T2) and secondary tillers on T2, 3rd primary tiller (T3), and other primary and secondary tillers.

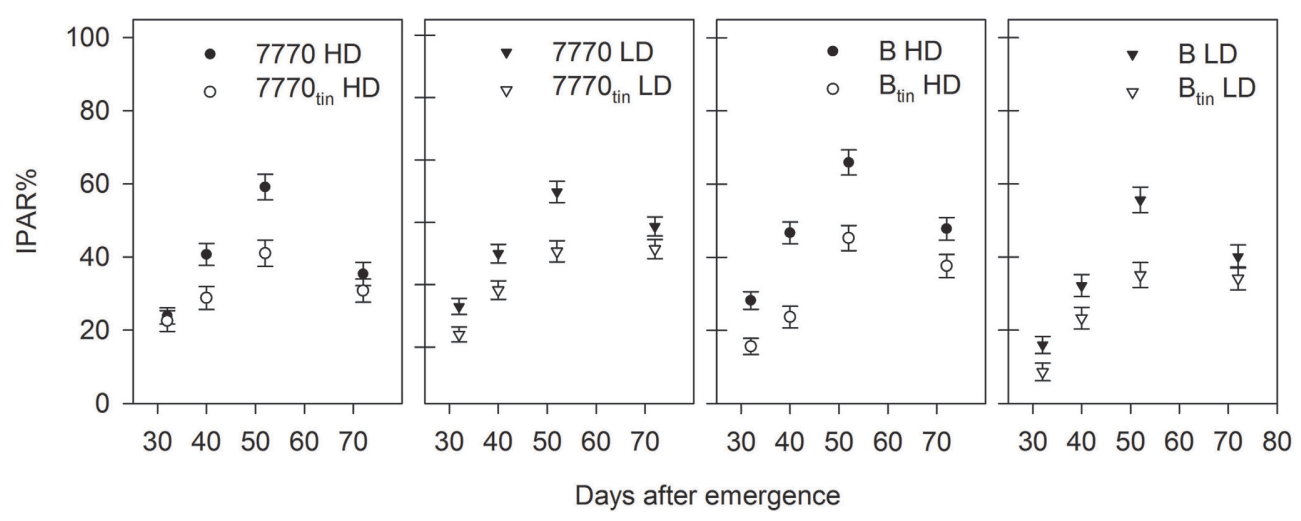

FIGURE 9 | Percentage of total intercepted photosynthetic active radiation (IPAR\%) in two pairs of near-isogenic lines contrasting for the tin gene $\mathbf{( 7 7 7 0 / 7 7 7 0 ~}_{\text {tin }}$ and $\left.B / B_{\text {tin }}\right)$ grown at high (HD) and low (LD) plant density at Canberra in 2012. Error bars show \pm one standard error.

\section{VERTICAL DISTRIBUTION OF LEAF AREA AND LIGHT}

The free-tillering lines produced greater total leaf area than the tin lines. In 2012, the anthesis LAIs (Z60-69; measured at 65 DAE) were 0.75 and 0.57 in lines 7770 and $7770_{\text {tin }}$, and 0.56 and 0.4 in lines $\mathrm{B}$ and $\mathrm{B}_{\text {tin }}(p<0.001, \mathrm{LSD}=0.13$; data not shown). Senescence was advanced at this stage, which contributed to the anthesis LAIs being low in 2012. In 2013, the LAIs at the start of spike emergence (Z50-52; LAIs measured between 106 and 117 DAE) were 6.53 and 5.58 in lines 7770 and $7770_{\text {tin }}$, and 9.26 and 5.6 in lines $\mathrm{B}$ and $\mathrm{B}_{\mathrm{tin}}$, respectively $(p=0.008, \mathrm{LSD}=$ 2.1). The LAIs declined subsequently due to senescence, and were statistically similar toward the end of anthesis (Z69-70; LAIs measured between 132 and 135 DAE) with a grand mean LAI of 4.2 $(p=0.15)$.

The vertical distribution of green leaf area differed between tin and non-tin lines, and this changed with senescence (Figure 11). At the start of spike emergence (Z50-52), the green leaf area at lower to mid-height of the canopy $(0.15$ to $0.45 \mathrm{~m})$ was significantly greater in the free-tillering compared to the tin lines $(p<0.02)$. However, toward the end of anthesis $(Z 69-70)$ the leaf area in the $0.3-0.45 \mathrm{~m}$ canopy layer was greater in tin lines
( $p=0.02)$ but similar for the sister-lines in the $0.15-0.3 \mathrm{~m}$ layer $(p=0.1)$.

The amount of PAR\% transmitted by the canopy declined exponentially with canopy depth (Figure 12). The light attenuation characteristics of the tin lines differed from those of the free-tillering lines in that the light extinction coefficient $k$ was greater in the $\operatorname{tin}$ lines at the start spike emergence $\left(7770_{\mathrm{tin}}: 0.64\right.$; 7770: 0.59; $\mathrm{B}_{\text {tin }}$ : 0.57; $\mathrm{B}: 0.41 ; \mathrm{r}^{2}>0.98$ and RMSD $<3.2$ for all exponential regressions), and lower in the tin lines compared to the free-tillering lines at the end of anthesis $\left(7770_{\mathrm{tin}}: 0.82\right.$; 7770: $0.98 ; \mathrm{B}_{\text {tin }}$ : 0.56; $\mathrm{B}: 0.69 ; \mathrm{r}^{2}>0.95$ and RMSD $<11.2$ for all exponential regressions).

\section{DISCUSSION}

Using specifically developed NILs contrasting for the tiller inhibition gene, tin, this study demonstrated that tin modifies different, seemingly genetically-unrelated, canopy architectural attributes such as the maximum number of shoots per plant and the distribution of organ sizes along shoots. Relationships between architecture and physiological functions observed in NILs contrasting for tin are discussed herein. 


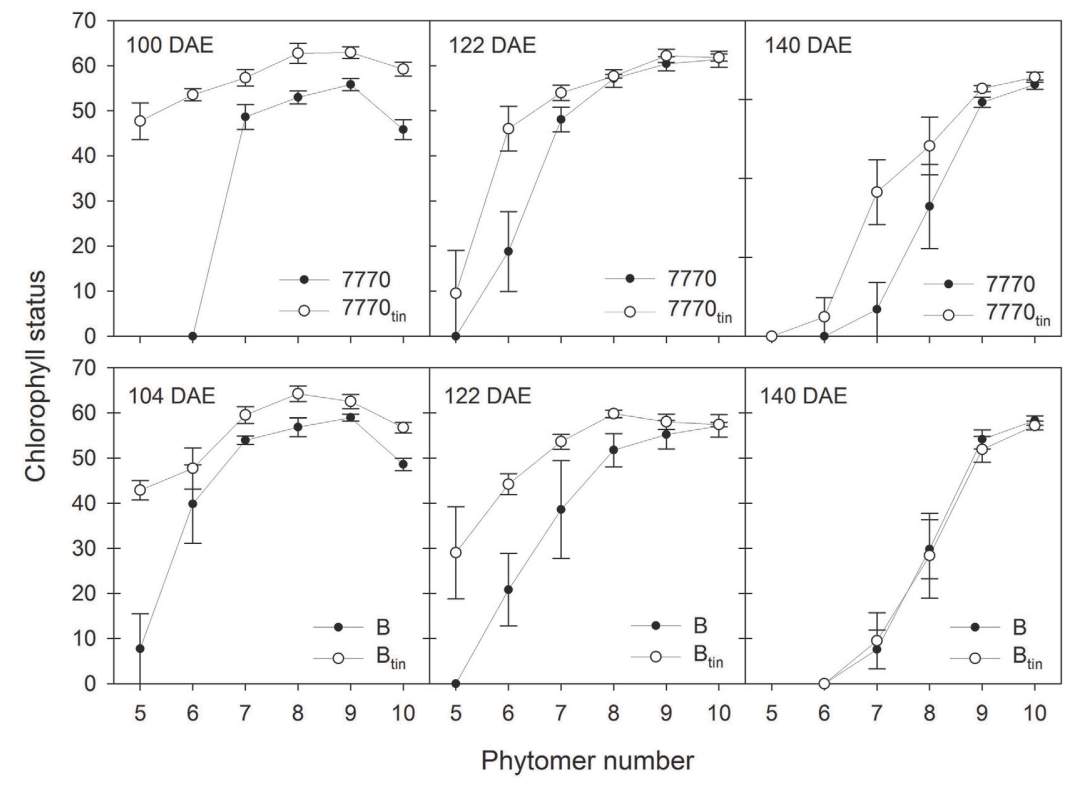

FIGURE 10 | Chlorophyll status (SPAD units) of main shoot leaves at mid to late booting stage (100-104 days after sowing; DAE), around early anthesis (122 DAE), and seed filling (140 DAE) in two pairs of

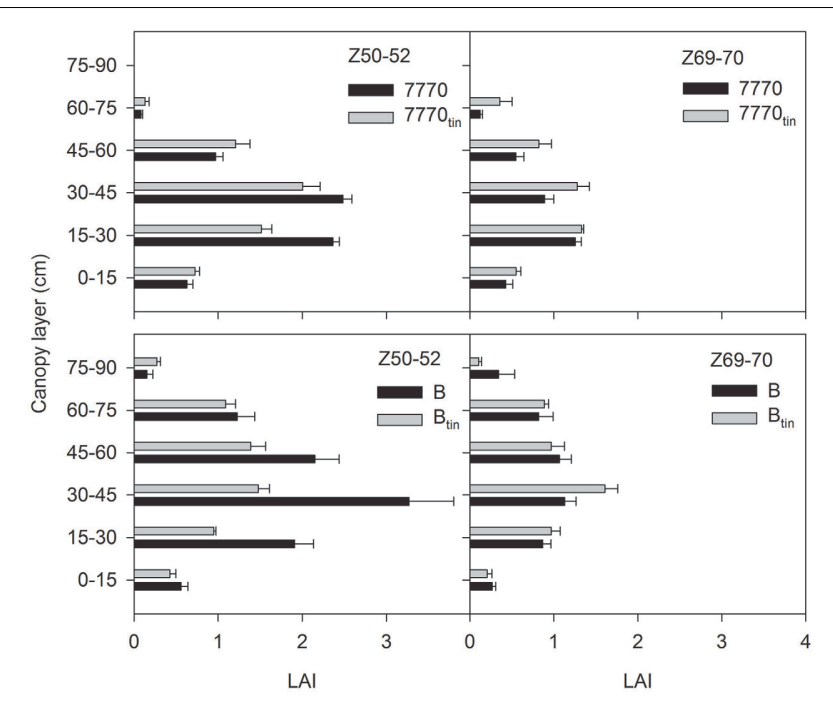

FIGURE 11 | Distribution of green leaf area index (LAI) with canopy height at the start of spike emergence (Z50-52) and late anthesis (Z69-70) in two pairs of near-isogenic lines differing in the tin gene $\left(\mathbf{7 7 7 0} / \mathbf{7 7 7 0}_{\text {tin }}\right.$ and $\left.B / \mathrm{B}_{\text {tin }}\right)$ grown at Canberra in 2013. Error bars show one standard error.

\section{PLASTICITY IN BUD BREAK}

Tillering in the tin lines ceased at a greater R:FR ratio than in the free-tillering lines, and this was independent of the observation that plant bases of tin lines received more radiation and were exposed to greater R:FR than the free-tillering sisters over much of the growing season. Later tiller buds in tin lines can break dormancy to initiate and grow though at reduced frequencies near-isogenic lines differing in the tin gene $\left(7770 / 7770_{\text {tin }}\right.$ and $\left.B / B_{\text {tin }}\right)$ grown at Canberra in 2013. Phytomer 10 corresponds to the flag leaf. Error bars show \pm one standard error.

(Figure 8) indicating that there is some plasticity for higherorder buds in response to environmental cues in the tin lines. However, it is still unclear to what extent such reduced levels of tillering plasticity in tin genotypes are mediated by light quality and especially R:FR signal transduction through the different phytochromes present in higher plants (Franklin and Whitelam, 2005). It will be interesting to further evaluate the tillering plasticity of tin genotypes in light and R:FR environments generated by the growing of plants on regular grids of different plant densities (Evers et al., 2006) or by manipulating light levels and/or R:FR artificially (Mandoli and Briggs, 1981; Casal et al., 1990) to explore the idea of a defined, genotype-specific R:FR threshold at which tillering ceases to be implemented in models of crop growth and development (Evers and Vos, 2013).

\section{THE RELATION BETWEEN BUD BREAK AND INTERNODE ELONGATION}

Elongating internodes are strong sinks for photo-assimilates, and Kebrom et al. (2012) hypothesized that precocious internode development in tin-containing lines contributes to the early arrest of tiller bud growth through sucrose starvation. Similar to the controlled glasshouse study by Kebrom et al. (2012), we observed under field conditions that the basal internodes of the tin lines elongated at lower phytomer ranks compared to the free-tillering sisters, though this was more pronounced in the Banks-derived line $\mathrm{B}_{\text {tin }}$ ( $\mathrm{a}$ sister-line of $\mathrm{B}_{\text {tin }}$ was evaluated by Kebrom et al., 2012) than in the Wyalkatchem-derived $7770_{\text {tin }}$. However, there was also environmental plasticity as internode elongation started at a lower phytomer rank in 2012 than in 2013 (Figure 6). Such plasticity has been previously observed in wheat where increased sowing depth and subsequently crown depth was associated with basal internodes elongating earlier, i.e., at a lower phytomer rank (Kirby, 1993). 


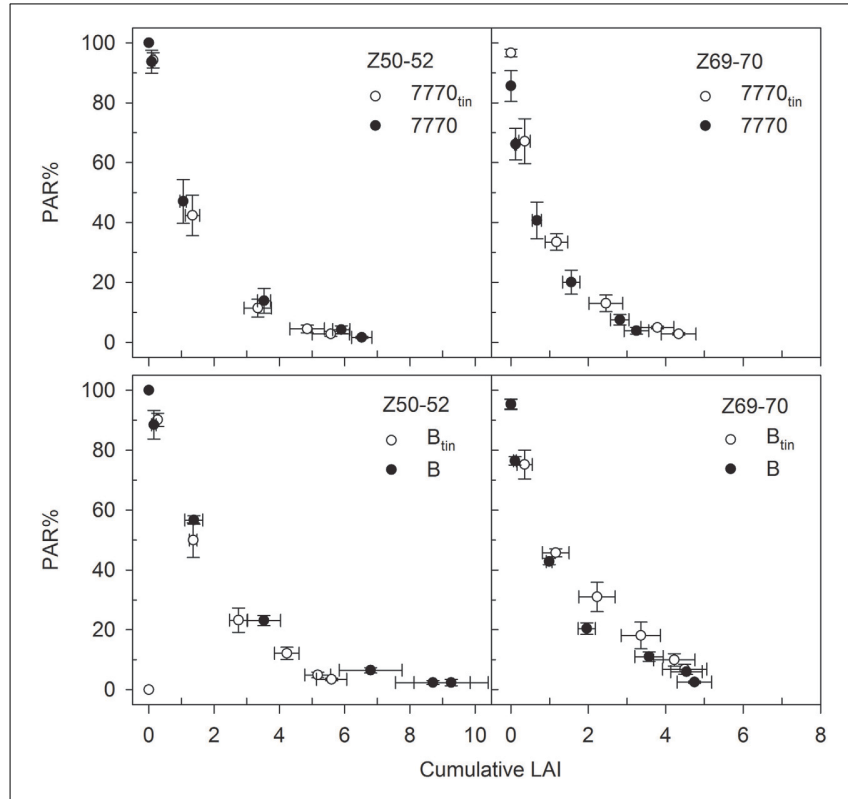

FIGURE 12 | Changes in the percentage photosynthetic active radiation (PAR\%) with canopy depth as indicated by the cumulative leaf area index (LAI) at the start of spike emergence (Z50-52) and late anthesis (Z69-70) in two pairs of near- isogenic lines differing in the tin gene $\left(\mathbf{7 7 7 0} \mathbf{7 7 7 0}_{\text {tin }}\right.$ and $\left.\mathrm{B} / \mathrm{B}_{\text {tin }}\right)$ at Canberra, 2013. The data pair $\mathrm{PAR} \%=100$ and $\mathrm{LAI}=0$ corresponds to the measurements taken above the canopy, and the lowest PAR\% and greatest LAls were measured at ground-level. Bi-directional error bars show \pm one standard error.

Up until now it is unclear if the greater R:FR ratio at which tillering ceased in tin genotypes, as discussed above, is indicative of an active process mediated by phytochrome or by resource limitation as suggested by Kebrom et al. (2012). The "nutritional hypothesis" (Assuero and Tognetti, 2010) for an early arrest of tiller bud growth is supported by the observation of low levels of sucrose in tiller buds that did not grow (Kebrom et al., 2012), and the recent finding that apical dominance in pea (Pisum sativum L.) was predominantly controlled by the strong demand of the shoot tip for sugars, which inhibited axillary bud outgrowth (Mason et al., 2014). Alternatively, genetic interaction between tin and genes responsible for photomorphogenic responses (Franklin and Whitelam, 2005) might modify the sensitivity to R:FR and consequently the photomorphogenesis of tin-containing lines compared to free-tillering lines. Map-based cloning of the tin gene is currently underway to identify the gene and physiological mechanism contributing to the observed variation in tillering response of tin-containing lines (W. Spielmeyer, personal communications).

\section{GREEN LEAF AREA IN LOWER CANOPY}

It has been shown that canopy light gradients are closely related to the vertical distribution of $\mathrm{N}$ per unit leaf area in wheat canopies (Bertheloot et al., 2008, 2012). Both tin lines maintained the green area of leaves in the lower canopy, and therefore leaf $\mathrm{N}$ content (Debaeke et al., 2006), for longer into the season. Prior to flowering, leaf $\mathrm{N}$ contents were greater in the tin lines (Figure 10). There is a strong relationship between leaf $\mathrm{N}$ content and the maximum (light-saturated) photosynthetic rate (Evans, 1989; Dreccer et al., 1998), which may have been greater in the tin lines just before flowering. Greater light penetration in the canopies of tin lines would have contributed to delaying senescence in the lower canopy (Figures 7, 9), and can improve radiation-use efficiency (Dreccer et al., 1998). Another factor for maintaining the leaf area in the lower canopy would be the improved availability of water and $\mathrm{N}$ per reproductive shoot associated with reduced tiller numbers and greater tiller economy. The greater leaf $\mathrm{N}$ contents of the upper-most leaves in tin lines observed prior to flowering may indicate increased availability of water and $\mathrm{N}$ per reproductive shoot rather than more available light. As the developing inflorescence represents a strong sink for $\mathrm{N}$ and carbon, improved tiller economy (Figure 7) and subsequent maintenance of leaf $\mathrm{N}$ content in the lower canopy (Figure 10) could be important traits for improving seed quality (protein content and seed size).

\section{LIGHT EXTINCTION}

Reduced light interception in the tin genotypes at maximum leaf area expansion, which typically occurs before anthesis when flag leaves are fully expanded (Moeller et al., 2007; Foulkes et al., 2001), can be explained by their smaller canopy size as associated with lower numbers of shoots and smaller LAIs. However, light interception would have been also influenced by the geometric and optical properties of the contrasting canopies as indicated by the different light extinction coefficients $(k)$ calculated for the NILs. Variation in $k$ for NILs contrasting in tin may be expected given the observed differences in distributions of organ sizes (Figures 4-6) and leaf area (Figure 11). Any interpretations of $k$ are notoriously difficult because the geometric and optical properties of canopies entail many interacting attributes (e.g., leaf size distribution, leaf angle, orientation, curvature as well as light reflectance and transmittance) changing dynamically in time and space, and some may even compensate for each other. The extinction coefficient $k$ changes concurringly: prior to spike emergence, we observed lower $k$-values in the smaller canopies of the tin lines compared to higher $k$-values in the larger canopies of the free-tillering lines while this was reversed after spike emergence. In contrast, Foulkes et al. (2001) speculated that small canopies may be "predisposed to have higher $k$, through having thicker, less transmissible leaves" (p. 14). Green (1987) expected "a continual decline of $k$ with age" (p. 219) due to ontogenic increases in leaf angle (i.e., downward movement of leaves). This contradicts our observation in which $k$ increased from prior to spike emergence until the end of spike emergence in all but one line $\left(\mathrm{B}_{\text {tin }}\right)$. This increase would be related to light interception by spikes as well changes in green area with plant age. Thus, $k$ is mainly useful to show that there are differences in optical properties but to dissect and further understand any sources of variation in $k$ in NILs contrasting for tin requires a more integrated approach that explicitly takes into account the spatial distribution of plant organs. The most feasible approach for achieving this is arguably spatially-explicit modeling of plant architecture, growth, development and physiological functioning called functional-structural plant (FSP) modeling (Vos et al., 2010; Evers and Vos, 2013). Based on existing FSP models of 
wheat (Evers et al., 2005), contrasting seasonal time-courses of tiller production and mortality as well as leaf area expansion and arrangement could be simulated to explore (i) the relationship with cumulative radiation interception, which is important for potentially achieving high productivity (Monteith, 1977), and (ii) the possible consequences for the timing of transpirational wateruse relative to anthesis and seed-filling, which is important for crop adaptation to water-limited environments (Passioura and Angus, 2010; Rebetzke et al., 2013).

\section{CONCLUSION}

This is the first study to quantify canopy architectural differences of NILs differing in the tiller inhibition gene tin. Using two contrasting genetic backgrounds grown in contrasting field environments, the study showed that the tin gene modifies the canopy architecture of wheat by increasing tiller economy and changing the distribution of organ sizes thereby varying the time course of resource-use. Associated with the early cessation of tillering in tin lines are reduced probabilities for later primary and higher-order tillers. The tin-containing genotypes intercepted less radiation as a consequence of reduced leaf area as well as differences in the vertical distribution of leaf area. The tin genotypes maintained the green area of leaves in the lower canopy for longer and this is likely to be related to lower light gradients and increased water and $\mathrm{N}$ availability per reproductive shoot. More radiation penetrated at canopy depth in tin lines, which could improve radiation-use efficiency. Spatially-explicit FSP modeling of canopy architecture, growth, and development is arguably the most feasible means to further elicit details of the relationships between earlier vs. later cessation of tillering in response to different R:FR signals, the evolving and expanding canopy structures post tillering, and the consequent light attenuation characteristics $(k)$ of the contrasting canopies explored here.

\section{ACKNOWLEDGMENT}

This study was funded by the Grains Research and Development Corporation (GRDC grant UT00024), and was conducted while the first author was a visiting scientist at CSIRO Plant Industry.

\section{REFERENCES}

Allard, V., Martre, P., and Le Gouis, J. (2013). Genetic variability in biomass allocation to roots in wheat is mainly related to crop tillering dynamics and nitrogen status. Eur. J. Agron. 46, 68-76. doi: 10.1016/j.eja.2012.12.004

Amthor, J. S. (2010). From sunlight to phytomass: on the potential efficiency of converting solar radiation to phyto-energy. New Phytol. 188, 939-959. doi: 10.1111/j.1469-8137.2010.03505.x

Assuero, S. G., and Tognetti, J. A. (2010). Tillering regulation by endogenous and environmental factors, and its agricultural management. Am. J. Plant Sci. Biotechnol. 4, 35-48.

Atsmon, D., Bush, M. G., and Evans, L. T. (1986). Stunting in gigas wheat as influenced by temperature and daylength. Aust. J. Plant Physiol. 13, 381-389. doi: 10.1071/PP9860381

Atsmon, D., and Jacobs, E. (1977). Newly bred gigas form of bread wheat (Triticum aestivum L.) - morphological features and thermo-photoperiodic responses. Crop Sci. 17, 31-35. doi: 10.2135/cropsci1977.0011183X0017000 $10010 \mathrm{x}$

Berry, P. M., Spink, J. H., Foulkes, M. J., and Wade, A. (2003). Quantifying the contributions and losses of dry matter from non-surviving shoots in four cultivars of winter wheat. Field Crops Res. 80, 111-121. doi: 10.1016/S03784290(02)00174-0
Bureau of Meteorology. (2014). Climate Data Online. Melbourne, VIC: Bureau of Meteorology. Available online at: http://www.bom.gov.au/climate/data/

Bertheloot, J., Andrieu, B., and Martre, P. (2012). Light-nitrogen relationships within reproductive wheat canopy are modulated by plant modular organization. Eur. J. Agron. 42, 11-21. doi: 10.1016/j.eja.2012.03.005

Bertheloot, J., Martre, P., and Andrieu, B. (2008). Dynamics of light and nitrogen distribution during grain filling within wheat canopy. Plant Physiol. 148, 1707-1720. doi: 10.1104/pp.108.124156

Borràs, G., Romagosa, I., van Eeuwijk, F., and Slafer, G. A. (2009). Genetic variability in duration of pre-heading phases and relationships with leaf appearance and tillering dynamics in a barley population. Field Crops Res. 113, 95-104. doi: 10.1016/j.fcr.2009.03.012

Bos, H. J., and Neuteboom, J. H. (1998). Morphological analysis of leaf and tiller number dynamics of wheat (Triticum aestivum L.): responses to temperature and light intensity. Ann. Bot. 81, 131-139. doi: 10.1006/anbo.1997. 0531

Casal, J. J., Sanchez, R. A., and Deregibus, V. A. (1986). The effect of plant-density on tillering - the involvement of R/FR ratio and the proportion of radiation intercepted per plant. Environ. Exp. Bot. 26, 365-371. doi: 10.1016/00988472(86)90024-9

Casal, J. J., Sanchez, R. A., and Gibson, D. (1990). The significance of changes in the red/far-red ratio, associated with either neighbor plants or twilight, for tillering in Lolium multiflorum Lam. New Phytol. 116, 565-572. doi: 10.1111/j.14698137.1990.tb00540.x

Davis, M. H., and Simmons, S. R. (1994). Tillering response of barley to shifts in light quality caused by neighboring plants. Crop Sci. 34, 1604-1610. doi: 10.2135/cropsci1994.0011183X003400060033x

Debaeke, P., Rouet, P., and Justes, E. (2006). Relationship between the normalized SPAD index and the nitrogen nutrition index: application to durum wheat. J. Plant Nutr. 29, 75-92. doi: 10.1080/01904160500416471

Dofing, S. M., and Karlsson, M. G. (1993). Growth and development of uniculm and conventional-tillering barley lines. Agron. J. 85, 58-61. doi: 10.2134/agronj1993.00021962008500010013x

Dreccer, M. F., Slafer, G. A., and Rabbinge, R. (1998). Optimization of vertical distribution of canopy nitrogen: an alternative trait to increase yield potential in winter cereals. J. Crop Prod. 1, 47-77.

Duggan, B. L., Richards, R. A., and van Herwaarden, A. F. (2005b). Agronomic evaluation of a tiller inhibition gene (tin) in wheat. II. Growth and partitioning of assimilate. Aust. J. Agric. Res. 56, 179-186. doi: 10.1071/ AR04153

Duggan, B. L., Richards, R. A., van Herwaarden, A. F., and Fettell, N. A. (2005a). Agronomic evaluation of a tiller inhibition gene (tin) in wheat. I. Effect on yield, yield components, and grain protein. Aust. J. Agric. Res. 56, 169-178. doi: 10.1071/AR04152

Duvick, D. N. (2005). "The contribution of breeding to yield advances in maize (Zea mays L.)," in Advances in Agronomy, Vol. 86, ed D. L. Sparks, 83-145. doi: 10.1016/s0065-2113(05)86002-x

Evans, J. R. (1989). Photosynthesis and nitrogen relationships in leaves of C3 plants. Oecologia 78, 9-19. doi: 10.1007/bf00377192

Evers, J. B., and Vos, J. (2013). Modeling branching in cereals. Front. Plant Sci. 4:399. doi: $10.3389 /$ fpls.2013.00399

Evers, J. B., Vos, J., Andrieu, B., and Struik, P. C. (2006). Cessation of tillering in spring wheat in relation to light interception and red:far-red ratio. Ann. Bot. 97, 649-658. doi: 10.1093/aob/mcl020

Evers, J. B., Vos, J., Fournier, C., Andrieu, B., Chelle, M., and Struik, P. C. (2005). Towards a generic architectural model of tillering in Gramineae, as exemplified by spring wheat (Triticum aestivum). New Phytol. 166, 801-812. doi: 10.1111/j.1469-8137.2005.01337.x

Forster, B. P., Franckowiak, J. D., Lundqvist, U., Lyon, J., Pitkethly, I., and Thomas, W. T. B. (2007). The barley phytomer. Ann. Bot. 100, 725-733. doi: $10.1093 / \mathrm{aob} / \mathrm{mcm} 183$

Foulkes, M. J., Scott, R. K., and Sylvester-Bradley, R. (2001). The ability of wheat cultivars to withstand drought in UK conditions: resource capture. J. Agric. Sci. 137, 1-16. doi: 10.1017/S0021859601001149

Franklin, K. A., and Whitelam, G. C. (2005). Phytochromes and shade-avoidance responses in plants. Ann. Bot. 96, 169-175. doi: 10.1093/aob/mci165

García del Moral, M. B., and García del Moral, L. F. (1995). Tiller production and survival in relation to grain yield in winter and spring barley. Field Crops Res. 44, 85-93. doi: 10.1016/0378-4290(95)00072-0 
Green, C. F. (1987). Nitrogen nutrition of wheat growth in relation to absorbed solar-radiation. Agric. Forest Meteorol. 41, 207-248. doi: 10.1016/01681923(87)90080-3

Ishikawa, S., Maekawa, M., Arite, T., Onishi, K., Takamure, I., and Kyozuka, J. (2005). Suppression of tiller bud activity in tillering dwarf mutants of rice. Plant Cell Physiol. 46, 79-86. doi: 10.1093/pcp/pci022

Kebrom, T. H., Chandler, P. M., Swain, S. M., King, R. W., Richards, R. A., and Spielmeyer, W. (2012). Inhibition of tiller bud outgrowth in the tin mutant of wheat is associated with precocious internode development. Plant Physiol. 160, 308-318. doi: 10.1104/pp.112.197954

Kirby, E. J. M. (1993). Effect of sowing depth on seedling emergence, growth and development in barley and wheat. Field Crops Res. 35, 101-111. doi: 10.1016/0378-4290(93)90143-B

Kirby, E. J. M., and Appleyard, M. (1987). Cereal Development Guide. Kenilworth: Arable Unit.

Kirby, E. J. M., and Faris, D. G. (1972). The effect of plant density on tiller growth and morphology in barley. J. Agric. Sci. 78, 281-288. doi: 10.1017/S0021859600069124

Klepper, B. L., Rickman, R. W., and Belford, R. K. (1983). Leaf and tiller identification on wheat plants. Crop Sci. 23, 1002-1004. doi: 10.2135/cropsci1983.0011183X002300050045x

Lauer, J. G., and Simmons, S. R. (1988). Photoassimilate partitioning by tillers and individual tiller leaves in field-grown spring barley. Crop Sci. 28, 279-282. doi: 10.2135/cropsci1988.0011183X002800020020x

Li, Y., Chen, D., Walker, C. N., and Angus, J. F. (2010). Estimating the nitrogen status of crops using a digital camera. Field Crops Res. 118, 221-227. doi: 10.1016/j.fcr.2010.05.011

Long, S. P., Zhu, X. G., Naidu, S. L., and Ort, D. R. (2006). Can improvement in photosynthesis increase crop yields? Plant Cell Environ. 29, 315-330. doi: 10.1111/j.1365-3040.2005.01493.x

Mandoli, D. F., and Briggs, W. R. (1981). Phytochrome control of 2 lowirradiance responses in etiolated oat seedlings. Plant Physiol. 67, 733-739. doi: 10.1104/pp.67.4.733

Mason, M. G., Ross, J. J., Babst, B. A., Wienclaw, B. N., and Beveridge, C. A. (2014). Sugar demand, not auxin, is the initial regulator of apical dominance. Proc. Natl. Acad. Sci. U.S.A. 111, 6092-6097. doi: 10.1073/pnas.1322045111

Mitchell, J. H., Chapman, S. C., Rebetzke, G. J., Bonnett, D. G., and Fukai, S. (2012). Evaluation of a reduced-tillering (tin) gene in wheat lines grown across different production environments. Crop Past. Sci. 63, 128-141. doi: 10.1071/CP11260

Mitchell, J. H., Rebetzke, G. J., Chapman, S. C., and Fukai, S. (2013). Evaluation of reduced-tillering (tin) wheat lines in managed, terminal water deficit environments. J. Exp. Bot. 64, 3439-3451. doi: 10.1093/jxb/ert181

Moeller, C., Pala, M., Manschadi, A. M., Meinke, H., and Sauerborn, J. (2007). Assessing the sustainability of wheat-based cropping systems using APSIM: model parameterisation and evaluation. Aust. J. Agric. Res. 58, 75-86. doi: 10.1071/AR06186

Monsi, M., and Saeki, T. (1953). Über den Lichtfaktor in den Pflanzengesellschaften und seine Bedeutung für die Stoffproduktion. Jpn. J. Bot. 14, 22-52.

Monteith, J. L. (1977). Climate and the efficiency of crop production in Britain. Philos. Trans. R. Soc. Lond. B Biol. Sci. 281, 277-294. doi: 10.1098/rstb.1977.0140

Passioura, J. B., and Angus, J. F. (2010). Improving productivity of crops in water-limited environments. Adv. Agron. 106, 37-75. doi: 10.1016/S00652113(10)06002-5

Prystupa, P., Slafer, G. A., and Savin, R. (2003). Leaf appearance, tillering and their coordination in response to $\mathrm{NxP}$ fertilization in barley. Plant Soil 255, 587-594. doi: 10.1023/A:1026018702317

Rebetzke, G. J., Chenu, K., Biddulph, B., Moeller, C., Deery, D. M., Rattey, A. R., et al. (2013). A multi-site managed environment facility for targeted trait and germplasm phenotyping. Funct. Plant Biol. 40, 1-13. doi: 10.1071/FP12180

Richards, R. A. (1988). A tiller inhibitor gene in wheat and its effect on plantgrowth. Aust. J. Agric. Res. 39, 749-757. doi: 10.1071/AR9880749
Richards, R. A., Rebetzke, G. J., Watt, M., Condon, A. G., Spielmeyer, W., and Dolferus, R. (2010). Breeding for improved water productivity in temperate cereals: phenotyping, quantitative trait loci, markers and the selection environment. Funct. Plant Biol. 37, 85-97. doi: 10.1071/FP09219

Ritchie, J. T. (1991). "Wheat phasic development," in Modeling Plant and Soil Systems, eds J. Hanks and J. T. Ritchie. (Madison, WI: American Society of Agronomy, Inc.), 31-54.

Ritchie, J. T., and NeSmith, D. S. (1991). “Temperature and crop development," in Modeling Plant and Soil Systems, eds J. Hanks and J. T. Ritchie (Madison, WI: American Society of Agronomy, Inc.), 5-29.

Sadras, V. O., and Rebetzke, G. J. (2013). Plasticity in tillering is associated with plasticity in yield of wheat. Crop Past. Sci. 64, 234-243. doi: 10.1071/ CP13117

Sadras, V. O., and Slafer, G. A. (2012). Environmental modulation of yield components in cereals: heritabilities reveal a hierarchy of phenotypic plasticities. Field Crops Res. 127, 215-224. doi: 10.1016/j.fcr.2011.11.014

Schmitz, G., and Theres, K. (2005). Shoot and inflorescence branching. Curr. Opin. Plant Biol. 8, 506-511. doi: 10.1016/j.pbi.2005.07.010

Sharma, R. C. (1995). Tiller mortality and its relationship to grain yield in spring wheat. Field Crops Res. 41, 55-60. doi: 10.1016/0378-4290(94)00109-P

Smith, H., Casal, J. J., and Jackson, G. M. (1990). Reflection signals and the perception by phytochrome of the proximity of neighboring vegetation. Plant Cell Environ. 13, 73-78. doi: 10.1111/j.1365-3040.1990.tb01301.x

Spielmeyer, W., and Richards, R. A. (2004). Comparative mapping of wheat chromosome $1 \mathrm{AS}$ which contains the tiller inhibition gene (tin) with rice chromosome 5S. Theor. Appl. Genet. 109, 1303-1310. doi: 10.1007/s00122-0041745-2

Stapper, M., and Fischer, R. A. (1990). Genotype, sowing date and plant spacing influence on high-yielding irrigated wheat in southern New-South-Wales.1. Phasic development, canopy growth and spike production. Aust. J. Agric. Res. 41, 997-1019. doi: 10.1071/AR9900997

Vos, J., Evers, J. B., Buck-Sorlin, G. H., Andrieu, B., Chelle, M., and de Visser, P. H. B. (2010). Functional-structural plant modelling: a new versatile tool in crop science. J. Exp. Bot. 61, 2101-2115. doi: 10.1093/jxb/erp345

Williams, J. H., Hook, R. A., and Hamblin, A. (2002). Agro-ecological regions of Australia: Methodologies for their derivation and key issues in resource management. Canberra, ACT, CSIRO Land and Water.

Zadoks, J. C., Chang, T. T., and Konzak, C. F. (1974). A decimal code for the growth stages of cereals. Weed Res. 14, 415-421. doi: 10.1111/j.13653180.1974.tb01084.x

Conflict of Interest Statement: The Associate Editor Sergey Shabala and the Reviewer Colin James Birch declare that, despite being affiliated to the same institution as the author Carina Moeller, the review process was handled objectively. The authors declare that the research was conducted in the absence of any commercial or financial relationships that could be construed as a potential conflict of interest.

Received: 18 June 2014; accepted: 21 October 2014; published online: 02 December 2014.

Citation: Moeller C, Evers JB and Rebetzke G (2014) Canopy architectural and physiological characterization of near-isogenic wheat lines differing in the tiller inhibition gene tin. Front. Plant Sci. 5:617. doi: 10.3389/fpls.2014.00617

This article was submitted to Plant Biophysics and Modeling, a section of the journal Frontiers in Plant Science.

Copyright (c) 2014 Moeller, Evers and Rebetzke. This is an open-access article distributed under the terms of the Creative Commons Attribution License (CC BY). The use, distribution or reproduction in other forums is permitted, provided the original author(s) or licensor are credited and that the original publication in this journal is cited, in accordance with accepted academic practice. No use, distribution or reproduction is permitted which does not comply with these terms. 